\title{
EVALUATING URBAN DESIGN STRATEGIES FOR CLIMATE CHANGE ADAPTATION IN LOS ANGELES
}

\author{
A Thesis \\ presented to \\ the Faculty of California Polytechnic State University, \\ San Luis Obispo
}

\begin{abstract}
In Partial Fulfillment
of the Requirements for the Degree

Master of City and Regional Planning in Architecture
\end{abstract}

and Master of Science in Engineering (Transportation Planning Specialization)

by

Kerby Olsen

April 2015 
(C) 2015

Kerby Olsen

\section{ALL RIGHTS RESERVED}


COMMITTEE MEMBERSHIP

TITLE:

Evaluating Urban Design Strategies for Climate

Change Adaptation in Los Angeles

AUTHOR:

Kerby Olsen

DATE SUBMITTED:

April 2015

COMMITTEE CHAIR:

Umut Toker, Ph.D.

Associate Professor of Architecture

COMMITTEE MEMBER:

Michael Boswell, Ph.D.

Professor of City and Regional Planning

COMMITTEE MEMBER: W. David Conn, D.Phil.

Professor Emeritus of City and Regional Planning 


\begin{abstract}
Evaluating Urban Design Strategies for Climate Change Adaptation in Los Angeles

Kerby Olsen
\end{abstract}

Human interference with the Earth's climate, through the release of greenhouse gasses (GHGs), is estimated to have already increased average statewide temperatures in California by $1.7^{\circ}$ Fahrenheit $(F)$, with a further $2.7^{\circ} \mathrm{F}$ of warming expected by mid-century. The negative impacts of increased temperatures may be especially acute in mid-latitude cities that currently enjoy a mild climate, such as Los Angeles (LA), which are projected to warm to a point that will significantly affect human health and well being. The built environment increases urban temperatures through building materials that readily absorb heat from the sun, a lack of vegetation, a lack of pervious surface area, and anthropogenic heat. Local governments can take action to help their cities adapt to future temperatures through changes to building materials, urban design and infrastructure. This study evaluates six urban design strategies for reducing temperatures and therefore adapting to increased heat in LA: cool roofs, cool pavements, solar panels, tree planting, structural shading and green roofs. The methods used in this analysis include a cost-effectiveness analysis, key stakeholder interviews, and case studies from other cities in the US. Findings indicate that cool roofs are the most cost-effective strategy for urban heat island mitigation, with cool pavements and tree planting also cost-effective. Findings from stakeholder interviews indicate that political feasibility is high for all strategies except structural shading, which was thought to be costly and difficult to implement. However, significant political barriers were also identified for tree planting and green roofs. Findings from four case studies indicate that climate adaptation policies should emphasize co-benefits, include flexible design standards, and provide financial or performance-based incentives for property owners or developers. Specific recommendations for implementing climate adaptation measures are provided for urban planners, policy makers, urban designers and architects in Los Angeles.

Keywords: Climate change adaptation, Los Angeles, urban heat island mitigation, cool roofs, green roofs, cool pavements, solar panels, tree planting, costeffectiveness analysis 


\section{ACKNOWLEDGMENTS}

I would like to thank several people for helping me through the multi-year process of writing this thesis. First and foremost, professor Umut Toker for keeping me motivated and on track. His systematic thinking and "no nonsense" approach proved invaluable to addressing this complex and broad topic. Professor Michael Boswell sparked my interest in this field through his own research and classes. In addition, he provided valuable comments and advice on the thesis and life in general. Professor David Conn helped me narrow down the thesis topic, and conducted a close reading of the text, both of which I am very grateful for. Like everything else in my life, this thesis would not have been possible without the love and support of my parents, Mary and James Olsen. 


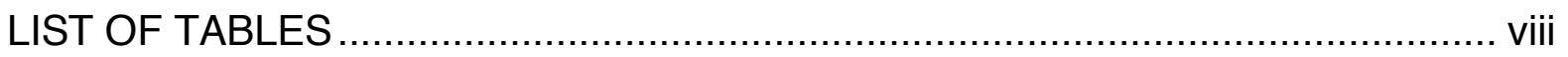

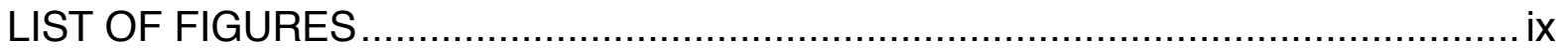
CHAPTER

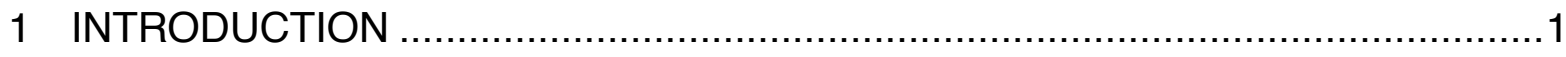

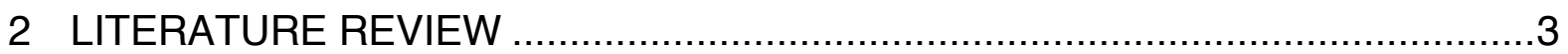

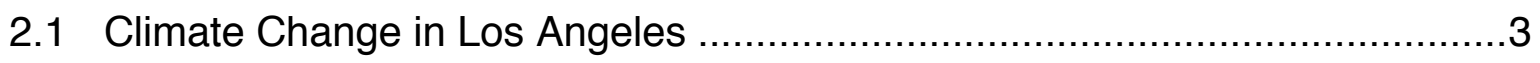

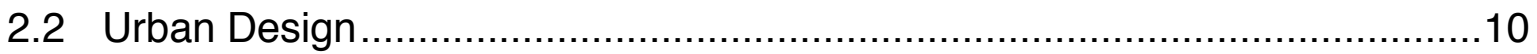

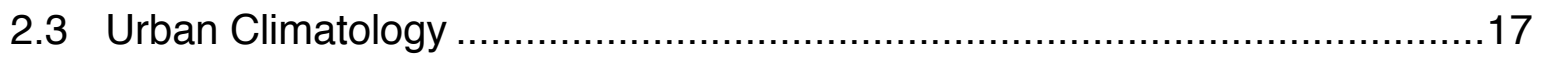

2.3.1 The Urban Heat Island Effect .....................................................18

2.3.2 Urban Heat Island Mitigation Strategies...........................................19

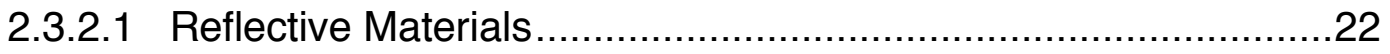

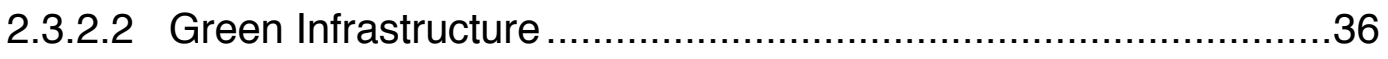

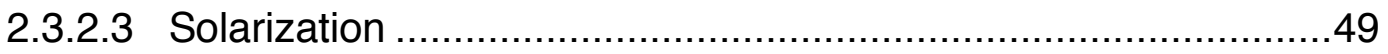

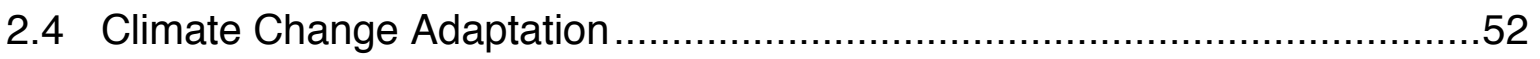

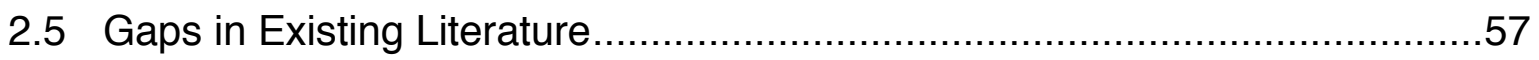

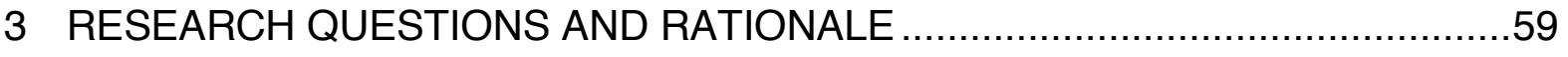

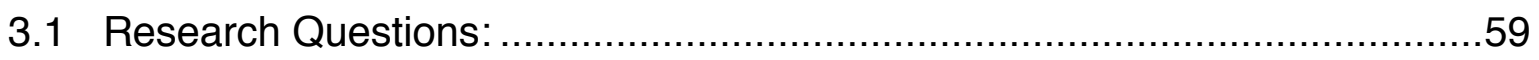

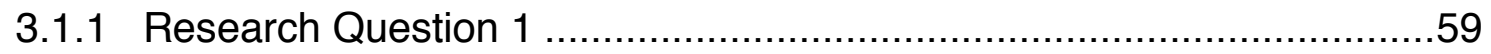

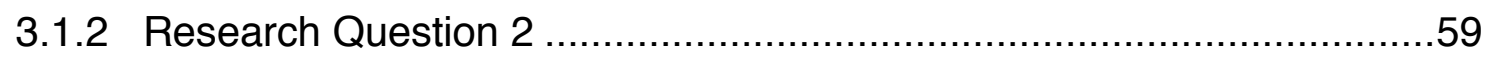

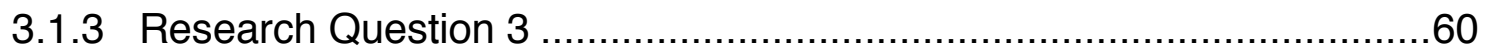

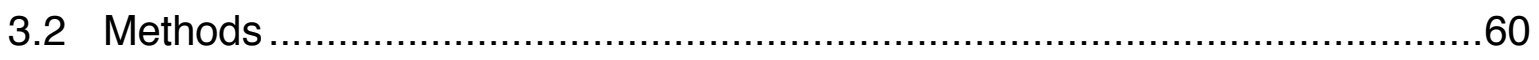

3.2.1 Cost-effectiveness Analysis ........................................................60

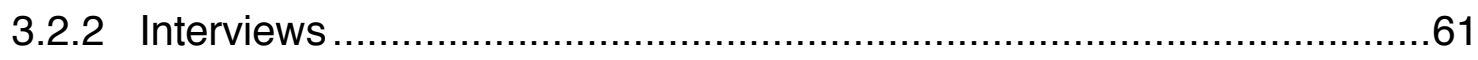

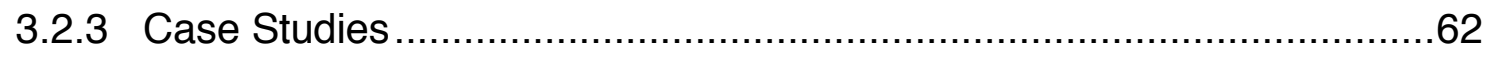

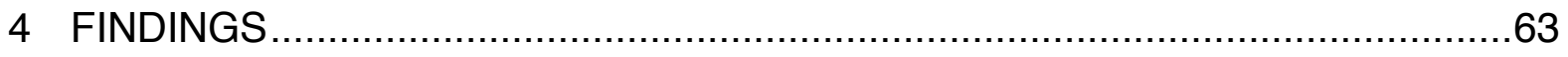

4.1 Cost Effectiveness Analysis................................................................

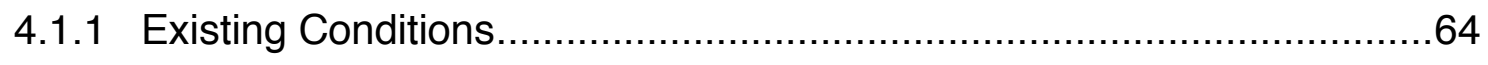




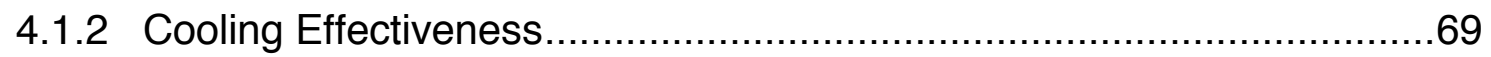

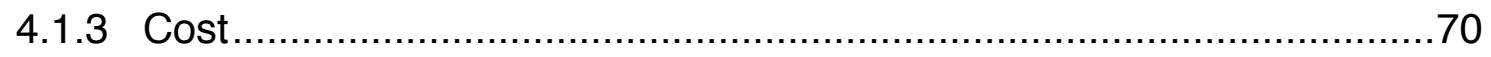

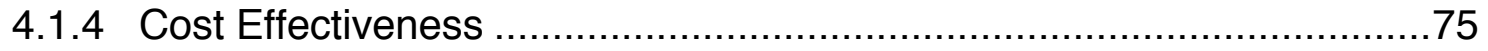

4.1.5 Cost Effectiveness Conclusions ..........................................................

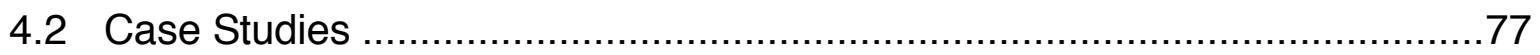

4.2.1 Case \#1: Cool Roofs Ordinance and Incentives in New York City.........77

4.2.2 Case \#2: Green Infrastructure in Seattle...........................................80

4.2.3 Case \#3: Mandatory Solar Panel Installation in Lancaster, CA. ............84

4.2.4 Case \#4: District of Columbia Stormwater Fee and Green Roof

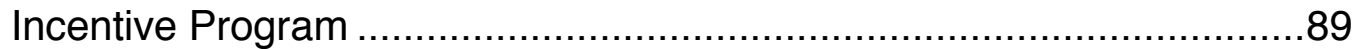

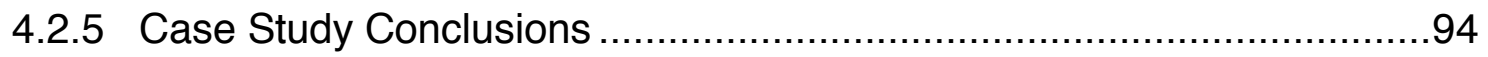

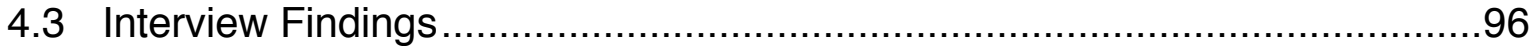

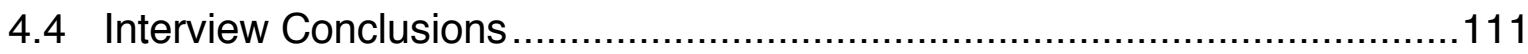

5 CONCLUSIONS AND RECOMMENDATIONS …......................................113

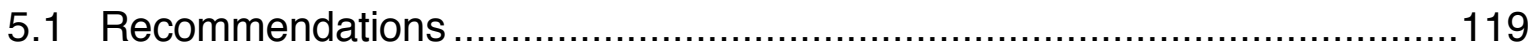

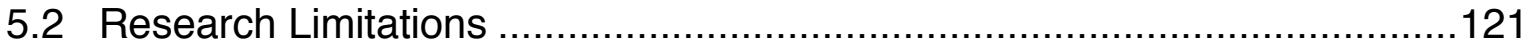

5.3 Opportunities for Further Study .....................................................122

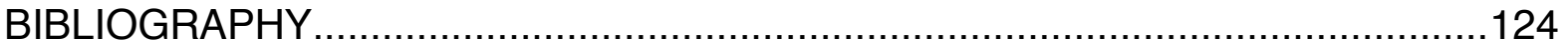




\section{LIST OF TABLES}

Table

Page

Table 1: Ranking of cooling effectiveness of heat island mitigation strategies in LA ...........21

Table 2: Cost premiums for cool varieties of common low-sloped roofing products ............29

Table 3: Comparative costs of various pavements and cool pavements ....................................35

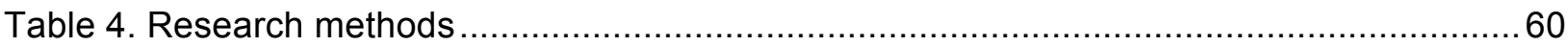

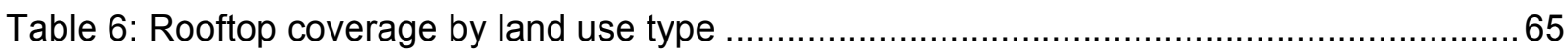

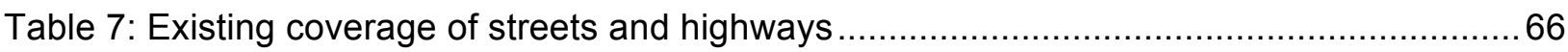

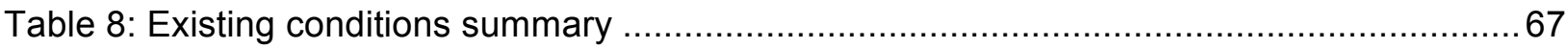

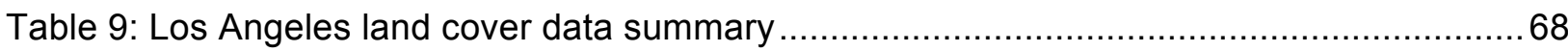

Table 10: Cooling effectiveness of UHIMSs in Los Angeles.................................................. 70

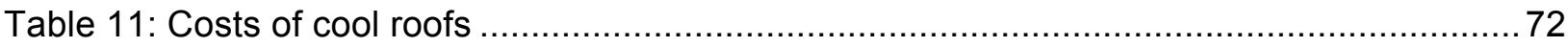

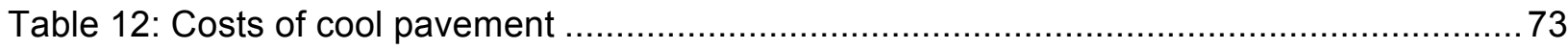

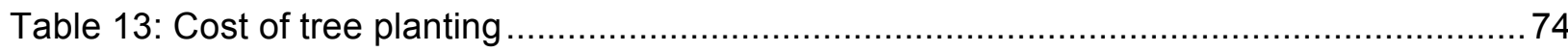

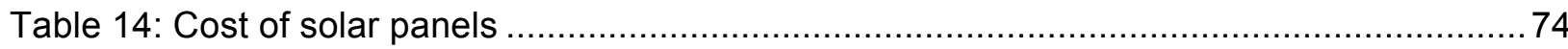

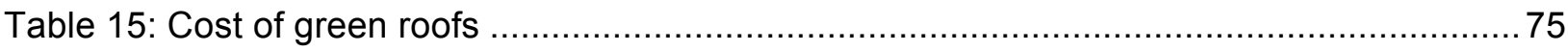

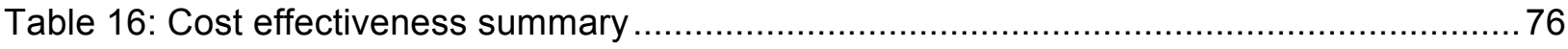

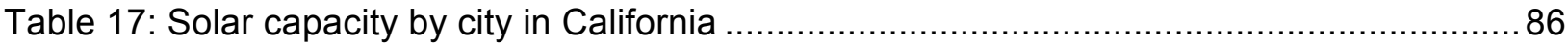

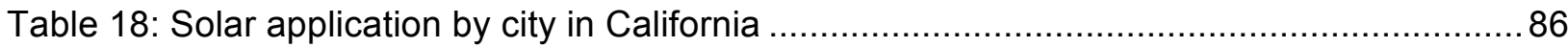




\section{LIST OF FIGURES}

Figure

Page

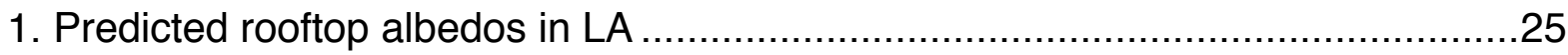

2. City of LA tree canopy cover by council district...............................................40 


\section{$1 \quad$ INTRODUCTION}

"We will respond to the threat of climate change, knowing that the failure to do so would betray our children and future generations". - President Barack Obama, Inaugural Address, January 21, 2013.

Human interference with the Earth's climate, through the release of greenhouse gasses (GHGs), is estimated to have already increased average statewide temperatures in California by $1.7^{\circ}$ Fahrenheit $(\mathrm{F})$, with a further $2.7^{\circ} \mathrm{F}$ of warming expected by midcentury (CCCC, 2012). Climate change will have varying impacts on cities and regions around the world. Some mid-latitude cities that currently enjoy a mild climate, such as Los Angeles (LA), are projected to warm to a point that will significantly affect human health and well-being, through an increase in the many negative impacts of increased temperatures and heatwaves. While the mitigation of future GHG releases is necessary and important for minimizing the future impacts of climate change, even the most optimistic forecasts predict that significant warming will occur regardless of human action. Therefore, adapting to this increase in temperature will become increasingly important in order to minimize the damage from those impacts.

The built environment increases urban temperatures through building materials that readily absorb heat from the sun, a lack of vegetation, a lack of pervious surface area, and anthropogenic heat. Local governments can take action to help their cities adapt to future climate change through physical changes to building materials, urban design and infrastructure. These climate change adaptation measures can range from water and 
energy conservation programs to the relocation of low-lying infrastructure away from the coast, to urban design policies such as reflective surfaces and green infrastructure. However, this study will focus specifically on urban design strategies for adapting to increased heat in LA.

Investments in adapting current infrastructure to mitigate increasing temperatures can take time to become effective (such as tree planting), and may be more cost effective to implement now than in the future. Therefore, it is important for cities with limited financial resources, such as LA, to evaluate and prioritize potential urban design investments in order to minimize social costs. In addition, some climate adaptation strategies are controversial, and may be met with political resistance. This study seeks to aid in the evaluation of climate adaptation strategies though the use of costeffectiveness analysis (CEA), key stakeholder interviews, and case studies of similar programs in other cities. In addition, a literature review details the most recent forecasts of climate change in LA and its potential impacts, as well as research into urban design, urban climatology, climate change adaptation, and urban heat island mitigation strategies. The cost-effectiveness of various climate adaptation strategies was determined through a review of the existing literature and a survey of implementation costs in California and LA. Political feasibility was determined through interviews with key stakeholders, such as planners and urban designers in the LA area. The results of this study are intended to be useful to policy makers, designers and city planners in the LA basin and other cities with climates similar to Southern California. 


\section{LITERATURE REVIEW}

\subsection{Climate Change in Los Angeles}

Los Angeles is a highly urbanized city of approximately 3,884,387 people, encompassing 469 square miles in Southern California (US Census, 2013). Los Angeles is the economic and cultural center of Southern California, and the greater LA metro area contributes nearly 755 billion in economic activity per year (US Conference of Mayors, 2012). In the coming century, climate change models project that LA will become significantly hotter and drier (Cayan et al., 2009). It is therefore critical to assess how this warming will affect the economic and social welfare of this important city, and how the negative impacts of warming might be mitigated.

Los Angeles's weather is currently very mild, and characterized by a SubtropicalMediterranean climate, with average low-temperatures in the high $40^{\circ} \mathrm{s} F$ in the winter and average highs in the upper $90^{\circ} \mathrm{s} \mathrm{F}$ in the summer, with an average of 14.93 inches of precipitation per year (NOAA, 2014). Well-known studies by the International Panel on Climate Change (IPCC) have attempted to derive projections of future global temperatures based on advanced computer models. Some of these models have also been "down scaled" to produce smaller scale projections that may be of greater use to state and local governments, including the LA area and California as whole. For example, Cayan et al. used six computer models to simulate future warming in the state of California (2009). These models produced a range of warming from $1.8^{\circ} \mathrm{F}$ to $5.4^{\circ} \mathrm{F}$ by 
mid-century, and 3.6 to $9^{\circ} \mathrm{F}$ by the end of the century. This study found that warming is "more moderate in the zone of about 50 kilometers $(\mathrm{km})$ from the coast, but rises considerably, as much as $7.2^{\circ} \mathrm{F}$ higher, in the interior landward areas as compared to the warming that occurs right along the coast" (Cayan et al., 2009, pg. 7). The climate models utilized by Hall et al. found even greater temperature increases in LA based on several scenarios for climate change due to human emissions of greenhouse gases (2012). These models project that average temperatures within downtown LA will increase anywhere from $.6^{\circ} \mathrm{F}$, to $6.5^{\circ} \mathrm{F}$ as early as 2050 , with greater warming toward the end of the century (Hall et al., 2012, p. 29). In addition, the incidence of "extreme heat" days (those over $95^{\circ} \mathrm{F}$ ) will increase from an average of 5.6 days per year today, to between 10 and 48 days per year by 2050 , under a "business as usual" GHG emissions scenario (Hall, et al., 2012, p. 29). This increase coincides with Cayan et al.'s prediction of statewide heatwaves increasing in frequency and magnitude, with a tendency for "multiple hot days in succession" (2009, p. 13). Cayan et al. estimate greater warming in the summer than in the winter, with summer temperatures increasing by $2.7^{\circ} \mathrm{F}$ to $10.8^{\circ} \mathrm{F}$ by the end of the century. These projected temperature increases will have various effects on the built and natural environments of Southern California and LA.

Climate change impacts on the natural environment

The impacts of climate change on the natural environment of the LA area should not be discounted. According to the US EPA, "natural ecosystems serve a variety of functions 
that provide people with necessary and valuable goods and services. For example, natural ecosystems maintain healthy air quality, regulate temperature and precipitation, prevent flooding, provide clean water for drinking and industrial use, maintain healthy and productive soil, pollinate wild plants and crops, maintain biological and genetic diversity...etc."(2013, p. 2). The natural environment of Southern California may experience increases in natural disasters such as wild land fires and floods, and a shift towards a more arid and desert-like climate. It is expected that "summer dryness will begin earlier, last longer and become more intense" (PEIR, 2009), with "a decided drying tendency" (Cayan et al., 2009, p. 13). Precipitation frequency is expected to decline, but intensity of precipitation events is projected to increase (Cayan et al., 2009, p. 14). This combination of a shorter wet season, less overall precipitation and more intense precipitation events will make droughts more frequent, water supplies more unpredictable, and wildfire risk higher. These climatic changes could have a significant effect on the potential habitat range and viability of local plant and animal species. In addition, sea level rise on the Southern California Coast "will be the same as global estimates" (Cayan et al., 2009, p. 14), ranging from 30 to $45 \mathrm{~cm}$ above year 2000 levels by 2050 . Rising sea levels may lead to greater erosion, and a loss of brackish water habitats along the coast.

\section{Climate change impacts on the built environment}

The effects of climate change on the urbanized areas of LA are similar to those of natural areas, such as increased heat, reduced precipitation, increased precipitation 
intensity, and sea level rise. However, the impacts of these effects are different in urban areas due to differences in vegetation, materials, and human alteration of the environment. The urbanization of land modifies the function of the natural environment in a variety of important ways, with impacts to virtually every natural physical process, including hydrology, ecosystem function and climate. As urban development in LA and the rest of the nation has encroached onto previously undeveloped land, important ecological functions have been lost. This development "has destroyed, degraded, and fragmented habitat" (US EPA, 2013, p. I). For example, the lack of pervious surface area in LA means that storm water cannot is not easily absorbed into the groundwater table, and instead must be routed to man-made storm water infrastructure, such as the concrete-lined LA river channel.

One of the most well studied climatic effects of the built environment on natural processes is the urban heat island effect (UHIE). The UHIE describes the tendency for urban environments, consisting of buildings, streets, and other man-made structures, to be warmer than their surrounding rural or less-developed areas, creating an "island" of warmth (Oke, 1973; Haider, 1997, p 99). The strength of the UHIE varies by city, but "the annual mean air temperature of a city with 1 million people or more can be 1.8$5.4^{\circ} \mathrm{F}\left(1-3^{\circ} \mathrm{C}\right)$ warmer than its surroundings. In the evening, the difference can be as high as $22^{\circ} \mathrm{F}\left(12^{\circ} \mathrm{C}\right)$ " (US EPA, 2013). Los Angeles, California, has been shown to produce one of the most extreme urban heat islands in the United States (Haider, 1997), with $92 \%$ more cooling-degree days than its surrounding undeveloped areas 
(cooling degree days are a measure of artificial cooling demand). Temperatures in downtown LA have been rising since the 1930 's, at a rate of approximately $.8^{\circ} \mathrm{F}$ per decade, for a total of $5^{\circ} \mathrm{F}$ between 1950 and 2000 (Akbari, et al., 1992). The primary consequences of the UHIE in LA include: increased human discomfort and health complications through exacerbated heat-related illnesses (Hajat and Kovats, 2008), reduced air quality through the amplification of photochemical smog (Horowitz, 1998), and wasted energy through increased cooling loads (Akbari, et al., 1991).

\section{Climate change impacts on public health}

Increasing temperatures tend to negatively affect public health. Multiple extreme heat days in succession can lead to the formation of "oppressive air masses", which are associated with "significant increases in heat-related mortality, especially from cardiac arrests, strokes, and other heat-related causes" (Vanos et al., 2014). In an average year, heat kills more people than any other natural disaster, accounting for approximately $20 \%$ of all deaths related to natural disaster between 1970 and 2004 (CDC, 2012; Borden \& Cutter, 2008). The young, the elderly, and those with compromised immune systems are the most vulnerable to heat impacts (Borden \& Cutter, 2008). Some of the increased mortality associated with heat is due to the direct effects of heat, such as heat stress. However, negative health effects are also due to the deterioration of air quality, which is exacerbated by increasing temperatures. 
Climate change impacts on air quality

Los Angeles is not known for good air quality; however, according to the South Coast Air Quality Management District (SQACMD), "the long-term trend of the quality of air we Southern Californians breathe shows continuous improvement, although the slowing rate of improvement in ozone levels causes concern" (SCAQMD, 2012). Despite a steady improvement in air quality, the SQACMD states that Southern California's air quality is "far from meeting all federal and State air quality standards and is, in fact, among the worst in the nation" (2012).

The impacts of the UHIE and climate change on air quality have been well studied, and are almost entirely negative. The California Climate Adaptation Strategy (2009) identifies the four primary effects that climate change can have on air pollution:

1) Increasing air temperatures increase ozone levels, which are formed by reactions between nitrogen oxides and hydrocarbons released from motor vehicles' combustion of fuel.

2) Increasing temperatures can change human behavior in ways that increase air pollution- for example, through increased fuel combustion to meet electricity demand for increased air conditioner use.

3) Climate change can affect patterns of air mixing and air flow that transport pollutants.

4) Increased temperatures can increase the emission of pollutants called volatile organic compounds from plants and vegetation ( $p$ 34). 
Both smog and ozone levels are affected by ambient temperature. Photochemical smog is the chemical reaction of sunlight, nitrogen oxides and volatile organic compounds. For every degree Fahrenheit of temperature increase, smog increases by approximately $3 \%$ (Horowitz, 1998). Ozone levels are unlikely to exceed EPA air quality thresholds below $74^{\circ} \mathrm{F}$, but increase dramatically above $74^{\circ} \mathrm{F}$ and reach unacceptable levels by $94^{\circ} \mathrm{F}$ (Akbari et al., 1991, p. 21). Therefore, efforts to reduce the urban heat island will simultaneously improve air quality and public health. According to Taha (2011), "for many areas in California with air quality problems, heat-island control measures could be a useful part of the plan to reduce energy demand and help reach ozone attainment."

\section{Climate change impacts on energy use}

Increasing temperatures in LA will greatly affect energy use, by altering human comfort and demand for artificial climate controls. In the winter, heating energy use may be slightly reduced; however this reduction in heating is likely to be dwarfed by an increase in cooling energy use in the summer. Akbari, et al. (1991) analyzed energy use data from 1986 and found that peak energy demand increased by a total of 300 megawatts $(\mathrm{MW})$, approximately $2-4$ percent of total demand, for each $1^{\circ} \mathrm{F}$ increase in temperature. This added electrical burden cost the LA basin $\$ 150,000$ per hour (Akbari et al., 1991, p. 18). Nationally, the "additional air-conditioning use caused by urban temperature increase is responsible for $5-10 \%$ of urban peak electricity demand (Rosenfeld, et al., 1995, p 255). 
Air quality, public health, and energy use are all inextricably linked with temperature. Global climate change induced warming will amplify LA's existing UHIE and long-term warming trend, leading to a degree of warming that could severely impact the city's energy demand, air quality, and public health. Therefore, understanding of the complex feedback between climate and the built environment is essential to developing tools and policies for climate change adaptation. This research cuts across various fields of study, but is primarily conducted within the fields of urban design, urban climatology, and climate change adaptation.

\subsection{Urban Design}

Urban design is defined as "the process of designing and shaping cities, towns and villages. Whereas architecture focuses on individual buildings, urban design addresses the larger scale of groups of buildings, of streets, and public spaces, whole neighborhoods and districts, and entire cities, to make urban areas functional, attractive, and sustainable” (“Urban design”, n.d.). According to Erell, Pearlmutter, and Williamson, "the term 'urban design' came into being about 50 years ago as design professionals realized that there were design issues which fell between and across the individual fields of architecture, landscape design and planning. Urban design became shorthand for the composition of architectural form and open space in a community context” (2011, p. 2). 
Ideally, urban design should respond to the local climate, in order to provide comfortable living conditions for people while minimizing the need for resource-intensive mechanical heating and cooling. Local climate is thought to be one of the main factors in the design of buildings and cities before the advent of mechanical air-conditioning, a concept known as "climatic determinism". Indeed, "many authors have proposed the idea that throughout the world, peoples have adopted building solutions and outdoor spaces that correspond to the prevailing climate to achieve desirable living conditions" (Erell et al., 2011, p. 70). However, Erell et al., propose that:

"older buildings and town planning traditions resulted from a complementary process of evolution driven by the physical environment, resources and climate mediated by social needs, institutional arrangements, taboos, and a good deal of trial and error, rather than conscious decision making (2011, p. 9)."

During LA's Spanish colonial period, from 1781 to 1821 , urban design was highly regulated, and intended to respond to climate. Both the location and the form of the original settlement of LA, known as 'El Pueblo de Nuestra Señora la Reina de Los Ángeles', was based on the Recompilación de las Leyes de Indias, the 'Laws of the Indies', as promulgated by King Phillip II of Spain in 1573. This comprehensive set of laws contained the legal system that pertained to the Spanish colonies, as well as a planning system complete with 148 ordinances to aid Spanish settlers in locating, building and populating settlements ('The Laws of the Indies', n.d.). The Laws of the 
Indies are even recognized as the first attempts at a general plan, and the first urban planning manual to reach the new world (Rosenburg, July 9, 2012).

According to James Rojas, the location of the Pueblo of Los Angles, founded in 1781, was required to be at least "twenty miles from the sea (to avoid pirates), near a freshwater source (the LA River), and close to a native tribe (for labor)" (As cited in Rosenberg, January 9, 2012). The original settlement included a town square, a church, and a rectilinear street grid system. Each settlement in the Spanish Colony of Alta California was required to contain four square-leagues of land, with one league in each cardinal direction emanating from the town center (Guinn, 1915). However, the streets themselves were required to be laid out at forty-five degrees from the cardinal directions. This alignment was thought to result in less heat gain for buildings, presumably based on experience from Spain, which has a very similar climate to California. The streets were required to be narrow, in order to provide shade. After the Mexican-American war of 1848-1849, the settlement of LA became part of the United States, and the Laws of the Indies and forty-five degree offset street grids were abandoned in favor of a less standardized planning process and a 'Jeffersonian' true North-South, East-West street grid. The confluence of these two grids can be seen at Hoover Street in downtown LA (Rosenberg, July 9, 2012).

Since the invention of mechanical air conditioning, urban dwellers in hot climates have had less incentive to design buildings and outdoor spaces with passive cooling 
strategies, such as those employed in Spanish colonial LA. The LA that we know today was largely built in the post- mechanical air conditioning era, and despite its relatively mild climate, often has a large demand for artificial cooling in the summer months. Artificial cooling demand is quantified using a measure called 'cooling degree days'. Over the last one hundred years, LA has averaged 1,153 cooling degree-days per year (WRCC, 2014). Artificial cooling requires energy, which in turn leads to the release of greenhouse gasses which contribute to further global warming. The green building movement, which seeks to design buildings with lower energy use and overall impact on the environment, has once again made climate considerations a driving force in contemporary architecture.

According to Erell et al. (2011), "the design of outdoor spaces requires an understanding of the local environment. This has traditionally been the role of architects, who have relied on intuition, personal experience and the example of others". The design of public and private spaces to minimize the effects of extreme heat has been practiced for thousands of years by cultures in hot climates, such as the Middle-East and North Africa. Mazouz and Zeroula's 1998 and 1999 studies of the indigenous towns of Algeria, combined with an analysis of solar angles, led to the recommendation that solar access be restricted to angles of 60 to 70 degrees or more, by means of controlling the street width and the use of cantilevered balconies. Los Angeles has historically had a very mild climate, and was largely built after the invention of air conditioning. Therefore, passive cooling strategies have not been widely implemented. 
However, as the temperature of LA moves closer to that of the Middle-east and North Africa, perhaps some of these design strategies could be adopted.

The design of buildings impacts the climate and experience of pedestrians in the immediate area of the building. When taken together, the design of the buildings of a certain area can affect the micro-climate of whole neighborhoods or areas. Givoni (1998) notes that "protection from sun and rain for pedestrians on the sidewalks can be provided by buildings with overhanging roofs, or colonnades, in which the ground floor is set back from the edge of the road, with the upper stories jutting out, supported by pillars (or other means). Such protection can create more pleasant climatic conditions for the urban pedestrian. Planned use of such means can be very important with respect to lessening the thermal load on pedestrians in the city's streets" ( $p$ xiii).

The field of urban design has, so far, lagged behind architecture in terms of emphasizing climate responsiveness. Erell et al., argue that the urban designer is best positioned to take climate in to account,

"Because there are few design projects where professionals from disciplines such as meteorology or biology are involved, the urban designer will in practice make the major decisions. With pressures to integrate the multitude of requirements into a working design, the time- and money-consuming approach of gathering and analyzing site-specific climate data is simply not possible" (2011, p. 11). 
Despite the clear role for urban designers in helping to produce buildings that are climate responsive, LA's urban design guidelines make few meaningful mentions of adapting to the local climate without the use of mechanical climate controls.

The Los Angeles Citywide Design Guidelines are not intended to be prescriptive requirements, but rather to promote "architectural and design excellence in buildings, landscape, open space and public space", as well as "the preservation of the City's character and scale" while "promoting design excellence and creative infill development solutions" (LA DCP, 2011). The City's design guidelines contain ten "principles of urban design", including:

1. Develop inviting and accessible transit areas.

2. Reinforce walkability, bikeability and well-being.

3. Nurture neighborhood character.

4. Bridge the past and the future.

5. Produce great green streets

6. Generate public open space.

7. Stimulate sustainability and innovation in our city.

8. Improve equity and opportunity.

9. Emphasize early integration, simple processes and maintainable solution.

10. Ensure connections (LA DCP, 2011). 
Climate change adaptation is not specifically mentioned in the Citywide Design Guidelines. However, a lead author of the Urban Design Guidelines stated that they address climate adaptation through "the language of sustainability", and that climate adaptation is "related to efficiency and reduction of consumption and production of waste" (Personal communication, May, 2014). Certainly, the energy efficiency of buildings can contribute to climate adaptation. By using less energy for mechanical heating and cooling, a building will produce less greenhouse gases. In addition, greater insulation will allow the interior of buildings to remain cooler despite higher outdoor temperatures. Specific requirements for resource efficiency and reduction of waste are laid out in the Los Angeles Green Building Code (LA GBC, 2011).

The LA GBC supplements the City's building code, and contains mandatory measures for: energy efficiency of lighting and heating ventilation and air conditioning (HVAC) systems, water efficiency of plumbing fixtures and landscapes, storm water drainage and retention, construction waste reduction, bicycle parking, and planning for solar panels and electric vehicles (LA GBC, 2011). While all of these measures are valuable for reducing the emissions of GHGs, and some are valuable for helping make the interiors of individual structures less reliant of artificial cooling, they do little to address citywide, ambient temperatures. In order to reduce temperatures citywide, the focus must be shifted from individual buildings to the interaction between the atmosphere and the built environment as a whole, including buildings, streets, sidewalks, and parks. Research on this interaction is conducted within the field of urban climatology. 


\subsection{Urban Climatology}

Urban climatology is the branch of climatology that deals with the canopy layer climate of urban or built-up areas. The canopy layer is the atmospheric layer closest to the ground, and is influenced by various micro-scale factors, such as buildings, trees, lakes and solar orientation, as opposed to macro-scale factors such as mountain ranges and jet-streams. Recently, urban climatologists have attempted to apply meteorological research to influence real-world urban planning. Researchers such as Oke and Taha are bridging the gap between climatology and urban planning through studies that model the interactions between the built environment and the canopy layer climate. For example, Oke (1998) determined the appropriate height to width ratio for buildings in mid-latitude cities was .4. Taha's 2013 study of UHIE mitigation strategies in LA ranked ten different UHIE mitigation strategies for their cooling effectiveness, and was intended to be utilized by planners in future decision making. Contemporary climatologists, such as Taha, create computer models of the small and medium scale micro-climate created by cities, and then manipulate various factors, such as surface reflectiveness or tree canopy cover, in order to gauge their effects on the climate. Mills (2006), states that "urban design strategies will create micro-climates that either accentuate or moderate the properties of the background climate. Thus, there is a clear role for an applied urban climatology in the planning of sustainable settlements (Mills, 2006, p 70)". One of the most important, and well-studied, concepts within applied urban climatology is the UHIE. 


\subsubsection{The Urban Heat Island Effect}

The UHIE is caused by a variety of interacting factors, including reduced evaporation in the city center (Bornstein, 1968), anthropogenic heat from buildings and vehicles (Haider, 1997), the thermal properties of building and paving materials, and changes to wind patterns caused by the buildings themselves (Oke, 1973). The exact causes and relative effects of the urban heat island effect tend to vary from city to city due to differences in local geography, climate and urban form (Myrup, 1969, p. 909). In general, the UHIE is caused by the greater potential thermal storage of the built environment, when compared to surrounding natural areas. Urban building materials, such as concrete, absorb heat from the sun and atmosphere during the day and release it at night. However, "It is not only the properties of the materials, but also the size and spatial arrangement of the surface areas that affects the storage of energy in the city" (Erell et al., 2011, p. 49).

The first well known study of the UHIE was conducted by Luke Howard, known as "the father of meteorology" in London in 1818 (Myrup, 1969). He found "the average urban temperature excess of London to be $2^{\circ} \mathrm{F}$, the excess being the greatest at night, when it amounted to $3.7^{\circ} \mathrm{F}$ " (As cited in Myrup, 1969). Recent studies have shown that different environmental factors may contribute to the UHIE differently throughout the day (Ryu \& Baik, 2011). The UHIE can have beneficial effects in colder, high-latitude cities, by reducing the need for indoor heating. However, in mid-latitude cities, such as LA, the UHIE tends to have predominantly negative effects (Haider, 1997, p. 99). 
Because the materials and design of the built environment contributes greatly to urban temperatures via the UHIE, it is possible that modifications to the built environment could play a major role in mitigating or attenuating future temperature increases. Several of these modifications, known as heat island mitigation strategies (HIMS), have been proposed for LA.

\subsubsection{Urban Heat Island Mitigation Strategies}

Due to LA's already extreme UHIE, there have been a number of HIMS proposed to help mitigate its effects. These HIMS, if implemented, may also help LA adapt to the future effects of global warming. HIMS have the direct effect of reducing indoor and outdoor ambient temperature through the reduction of heat transfer from the sun and/or atmosphere. In addition to the direct effect of reducing temperature, HIMS can also have indirect effects, including: reduced cooling demand and energy use, improved air quality, reduced heat-related sickness and mortality, and energy production through solar photovoltaics.

Vanos et al. studied the potential impacts of urban heat island mitigation strategies on public health (2014). They found that a 10 percent increase in urban surface reflectivity, alone or in combination with a 10 percent increase in vegetative surface cover, would decrease heat-related mortality by 1 percent. However, they also found that a 20 
percent increase in urban surface reflectivity would decrease mortality by $21 \%$, saving up to 22 lives per year (Vanos et al., 2014).

Several studies have ranked HIMS for their relative effectiveness at the community scale in LA (Taha, 2013), and the nation as a whole (Sailor \& Dietsch, 2005), while others have measured the actual effectiveness of previously implemented meso-scale strategies. Taha (2013) studied the direct effects of ten HIMS, in order to determine which strategies had the greatest effectiveness at reducing air temperature, as well as the greatest indirect effects. The HIMS studied included:

1) Increased albedo on urban surfaces (roofs, walls, pavements, streets);

2) Moisture and runoff control (control of impervious surface areas);

3) Increased vegetation cover for both a) shading and b) evapotranspirative cooling (for buildings, parking lots, and streets);

4) Structural shading (control of view factor),

5) Photovoltaics;

6) Other passive/active solar systems (water heaters, space heaters and coolers);

7) Green roofs / green walls; and

8) Control of anthropogenic heating.

Taha's results are summarized in table 1. 
Table 1: Ranking of cooling effectiveness of heat island mitigation strategies in LA

\begin{tabular}{|l|l|l|}
\hline Rank & Heat island mitigation strategy & $\begin{array}{l}\text { Change in Air } \\
\text { Temperature }\left({ }^{\circ} \mathrm{C}\right)\end{array}$ \\
\hline 1 & Increase roof albedo by .4 & -.73 \\
\hline 2 & Increase pavement albedo by .2 & -.50 \\
\hline 3 & Increase roof albedo by .2 & -.43 \\
\hline 4 & Increase Street/Highway albedo by .15 & -.31 \\
\hline 5 & Increase pavement albedo by .1 & -.26 \\
\hline 6 & Increase street/Highway albedo by .07 & -.17 \\
\hline
\end{tabular}

Source: Taha, H., 2013

The proposed heat island mitigation efforts are at the urban design scale, meaning that they are design strategies meant to be implemented across many structures, and in the spaces between buildings, such as streets, sidewalks and alleys. These proposed efforts can be categorized into four major groups: green infrastructure, reflective surfaces, solarization, and passive cooling, which are explored in detail. None of these strategies has so far been implemented on a large scale within the city of LA; however, some have been implemented on a large scale in other cities (Lieu et al. 2012). The four HIMS are defined as follows:

1) Reflective surfaces: The use of highly reflective materials, including roof coatings and pavements, which reflect a larger proportion of the sun's energy back into the atmosphere (Horowitz, 2009). 
2) Green Infrastructure: Strategies that call for the planting of green vegetation on streets, yards, and parking lots, which will provide shade while also converting the sun's energy via photosynthesis ( $\mathrm{Ng}$, et al. 2012).

3) Solarization: strategies that call for a large scale deployment of solar photovoltaic panels on roof tops, so that they might convert sunlight into electricity, simultaneously feeding the electricity grid, and cooling the building (Taha, 2011)

4) Passive cooling: Building and urban design strategies that utilize shade structures, massing strategies, building height-to-width ratio, and other methods to cool individual buildings, streets, and the spaces between them (Erell et al., 2011).

\subsubsection{Reflective Materials}

One of the fundamental drivers of the UHIE is the low albedo of materials used in the built environment. Los Angeles as a whole was found to have an overall average albedo of .2, a difference of .09 from its rural areas (Haider, 1997). This lower albedo causes the urban environment to retain a greater share of the sun's energy than surrounding, undeveloped areas, as less light is reflected back into the atmosphere. Various authors have suggested that the key to reducing the UHIE is to increase the urban albedo, typically through "cool roofs" or "cool concrete", which are both highly reflective versions of traditional materials. A cool roof reflects more of the sun's rays, rather than absorbing them. Cool pavements lower pavement temperature "because more of the sun's energy is reflected away, and there is less heat at the surface to absorb into the pavement" (US 
EPA, 2008, $p$ 15). These two approaches to UHIE reduction share the same fundamental mechanism (reflecting a greater portion of the sun's energy), but differ greatly in terms of materials, policy and implementation.

\section{Cool roofs}

Cool roofs are rooftops with high solar reflectance and high thermal emittance. Solar reflectance is the "fraction of solar energy that is reflected by the roof" and thermal emittance is "the relative ability of the roof surface to radiate absorbed heat". Both properties are rated on a scale from 0 to 1 , with 1 being the most reflective or emissive (CRRC, n.d.). Roofing materials that can be made to be "cool" include: white coatings, single-ply white membranes, cap sheets that cover built-up roofing materials, metal roofs, shingles, and foam coatings, among others (CRRC, n.d.). California has been a leader in developing programs to incentivize these 'cool' roofing products.

Beginning in 2001, the State of California, and various utilities, began offering incentives for installing 'cool' products on low-slope commercial buildings (Gartland, 2008). In 2005, revised American Society of Heating, Refrigeration, and Air Conditioning Engineers (ASHRAE) building standards S90.1 required a minimum 'aged' reflectance of .55, increasing in 2008 and 2013. In addition, cool surfaces have been included as tradable smog-offset credits in LA. California Assembly bill 296 (2011) directed the California Environmental Protection Agency (Cal EPA) to define the UHIE, and the 
California Department of Transportation to develop a standard specification for reflective, "cool" pavements (Cal leg info, n.d.).

The City of LA has since adopted even more stringent cool roof requirements, with the passage of ordinance number 183149, which amends section 99.01.101.3 and 99.04.106.5 of Article 9, Chapter IX of the Los Angeles Municipal Code to require that "every new building, and every building alteration with a construction value of greater than $\$ 200,000$, must have a solar reflectance index of 75 for low-slope roofs $(<2: 12)$, and 16 for sloped roofs $(>2: 12)$. The predicted albedo of LA is shown in figure 1 (Reproduced from Weiss, Woods and Levinson, 2014, p. 36). 


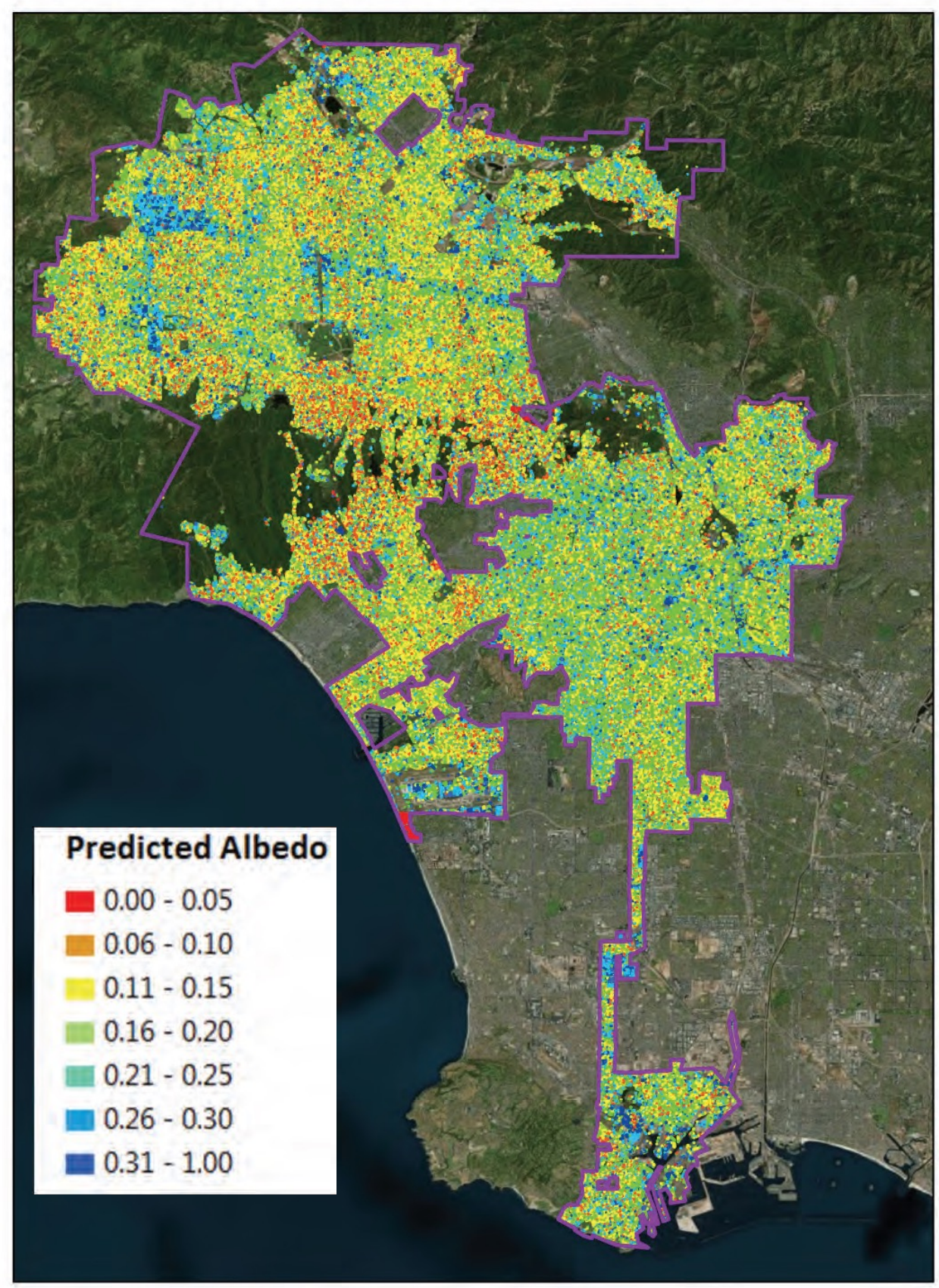

Figure 1. Predicted rooftop albedos in LA.

The urbanized area of LA contains a high proportion of buildings and rooftops. Weiss, Woods and Levinson (2014) used remote sensing to determine that LA has $1,130,120$ 
rooftops, with a total roof area of $222.4 \mathrm{~km}^{2}$ and a mean roof albedo of .17 , plus or minus .08 . The total fraction of the city covered by roofs was determined to be $18 \%$, with small roofs $\left(<400 \mathrm{~m}^{2}\right)$ comprising $60-70 \%$ of all rooftops, and large roofs $\left(>1,000 \mathrm{~m}^{2}\right)$ comprising $15-25 \%$ of roofs. They also found that large commercial roofs tend to use more reflective materials, with albedos up to .7. This may be a result of prescriptive cool roofs requirements that were incorporated in the revised ASHRAE building standards S90.1.

The effects of reflective roofing materials on building surface and internal temperatures are well understood. According to Guyenet (2010), when sunlight hits a roof, "the remainder of the solar energy, that which is neither reflected nor re-emitted, is transferred to the building as heat or is convected by ambient breezes into the surrounding atmosphere, heating the surrounding air" $(p 1)$. Therefore, the heat absorbed by roofing materials affects the surface temperature of the roof, as well as the internal temperature of the building that the roof covers. For example, Taha (2009) found that "a white elastomeric coating (albedo .72) was $45^{\circ} \mathrm{C}$ cooler than a black coating (albedo .08) in the early afternoon of a clear day in the summer". In hot climates, it is beneficial to reduce the internal temperature of buildings, in order to reduce artificial cooling demand. Parker, Barkaszi, Chandra and Beal (1995) measured the effects on energy use of changing the roof color of nine homes in Florida, and found that the midsummer cooling load was reduced an average of $19 \%$ by light colored materials. 
When reflective materials are used over a large area, the cumulative effects can be significant. A 2012 study of the Andalusia region of Spain found that a large-scale implementation of cool roofs could potentially save $295,000 \mathrm{kWh}$ per year of energy, due to cooling savings (Boixo, Diaz-Vicente, Colmenar, \& Castro, 2012). Horowitz (2011) claims that LA could save 30 million dollars per year, based on electricity costs alone, through large-scale implementation of cool roofs, due to a $15 \%$ reduction in overall energy use. Taha (2009) found that increasing the albedo of the LA urban basin by .13 could decrease temperature by 2 to $4^{\circ} \mathrm{C}$.

\section{Costs of cool roofs}

Cool roof options, and costs, depend on the type of roof and roof material to be used. The non-residential roofing materials market is dominated by built-up, modified bitumen, and single-ply membrane roofs. Built-up roofs, which are composed of layers of "saturated felts...between which alternate layers of bitumen are applied" make up 46 percent of new roof sales in the pacific region, which includes LA (Dodson, 2001). Modified bitumen roofs, which consist of "polymer-modified bitumen often reinforced with various types of maters, films, foils and mineral granules", make up 10 percent of new roof sales. Single-ply membranes, which include only one layer of "thermoset, thermoplastic, or polymer-modified bituminous compounds" make up 18 percent of new roof sales (Dodson, 2001). The residential roofing market is dominated by asphalt shingles. Asphalt shingles are "easy to install, relatively affordable, last 20 to 50 years and are recyclable in some areas" (Roof shingle, n.d.). 
Levinson, Akbari, Nonopacki and Bretz evaluated the cost premium of cool roof coating as part of their 2002 study "Inclusion of cool roofs in nonresidential title 24 prescriptive requirements". They considered only the incremental costs of cool roofing products, as compared to the equivalent conventional product, and found that cost premiums ranged from zero, for metal roof paint and roof coatings to $\$ .2 / \mathrm{sq}$. ft. for cementitious white coatings (which replace ballasted built-up roof coatings). Levinson et al.'s full cost premium results are reproduced in table 2 .

A roofing contractor conducted an analysis of the cost premium of "cool" roof shingles for residential buildings, using published cost data from a major roofing manufacturer. They found that cool shingle roofs cost approximately $\$ .64$ more per square foot then conventional shingle products (Trinity Exteriors, Inc., 2010). 
Table 2: Cost premiums for cool varieties of common low-sloped roofing products

\begin{tabular}{|l|l|l|}
\hline \multicolumn{1}{|c|}{ Roofing product } & \multicolumn{1}{|c|}{ Cool variety } & Cost premium $\mathbf{( \$ / \mathbf { f t } ^ { 2 } )}$ \\
\hline Asphalt shingle & $\begin{array}{l}\text { Use reflective asphalt } \\
\text { shingle }\end{array}$ & .64 \\
\hline Ballasted BUR & Use white gravel & Up to .05 \\
\hline $\begin{array}{l}\text { BUR with smooth asphalt } \\
\text { coating }\end{array}$ & $\begin{array}{l}\text { Use cementitious or other } \\
\text { white coatings }\end{array}$ & .10 to .20 \\
\hline $\begin{array}{l}\text { BUR with aluminum } \\
\text { coating }\end{array}$ & $\begin{array}{l}\text { Use cementitious or other } \\
\text { white coatings }\end{array}$ & .20 to .20 \\
\hline $\begin{array}{l}\text { Single-ply membrane } \\
\text { (EPDM, TPO, CSPE, PVC) }\end{array}$ & Use a white membrane & .00 to .05 \\
\hline $\begin{array}{l}\text { Modified bitumen (SBS, } \\
\text { APP) }\end{array}$ & $\begin{array}{l}\text { Use a white coating over } \\
\text { the mineral surface }\end{array}$ & Up to .05 \\
\hline $\begin{array}{l}\text { Metal roofing (both painted } \\
\text { and unpainted) }\end{array}$ & $\begin{array}{l}\text { Use a white or cool-color } \\
\text { paint }\end{array}$ & .00 to .05 \\
\hline $\begin{array}{l}\text { Roof coatings (dark color, } \\
\text { asphalt base) }\end{array}$ & $\begin{array}{l}\text { Use a white or cool-color } \\
\text { coating }\end{array}$ & .00 to .10 \\
\hline Concrete tile & Use a white or cool-color tile & .00 to .05 \\
\hline Fiber-cement tile & Use a white or cool-color tile & .05 \\
\hline Red clay tile & Use a cool red tile & .10 \\
\hline Source: Levinson et al., 2002; Trinity Exteriors, Inc., 2010 & \\
\hline
\end{tabular}

\section{Arguments against cool roofs}

Arguments against cool roofs cite the possibility of increased glare on surrounding buildings, the increased need for heating in the winter, and the belief that more focus should be paid to greenhouse gas mitigation than to climate adaptation (Tuhus-Dubrow, 2014). However, a study by Levinson and Akbari found that in the United States, the winter heating penalty is typically small compared to the summer cooling benefit (2010). 


\section{Reflective pavements}

Highly reflective pavement materials have also been proposed as a means of increasing the albedo of urban areas. The surface area of LA, and other large cities, contains a high percentage of roads, freeways, parking lots and other paved areas. Urban designers in LA estimate that the City has approximately 6,500 miles of streets and 900 miles of alleys, comprising 61 square miles, or $12 \%$ of the land area. Parking lots, sidewalks and sidewalks further contribute to the City's overall paved surface area, although the exact percentage has yet to be determined. Studies of the paved surfaces of four cities by the Lawrence Berkeley National Laboratory found that the total paved surface area ranged from $29 \%$ for Houston, TX, to $45 \%$ for Sacramento, CA (Rose, Akbari \& Taha, 2003). These surfaces are composed primarily of concrete or asphalt.

Concrete and asphalt are both composed primarily of sand, stone and a binding material. In asphalt, the binding material is tar (which, in LA, is composed partially of recycled tires), while in concrete the binding material is Portland cement. These two types of pavement have very different characteristics, and are typically used in different situations. Asphalt tends to be about half the price of concrete, but lasts about half as long and requires more frequent repairs. Concrete is typically used for sidewalks and freeways, while asphalt is used for most surface roadways and parking areas (Akbari \& Levinson, 2001). Concrete lasts longer but is more expensive to install, and repairs can be much more costly. The two materials also perform very differently in terms of albedo and their effects on the urban heat island. Akbari and Levinson (2001) measured the 
albedo of various concrete mixes and found that they ranged from an average of .59 for "smooth", white-colored mixes to as low as .05 after simulated soiling. Asphalt pavement albedo ranges from .1 for aged asphalt to .05 for new asphalt (Akbari \& Levinson, 2001). Asphalt albedo tends to increase over time, while concrete albedo tends to decrease over time. The albedo of both asphalts and pavements can also be increased in several ways.

According to Gregerson (2010), potential solutions for increasing pavement albedo include:

- "Chip seals and sand seals with light-colored aggregates -essentially surface treatments consisting of single or multiple applications of asphalt and aggregate on existing pavement. This low-cost option is commonly employed to treat weathered pavements.

- Surface gritting with light-colored aggregate - a method that spreads aggregate over newly placed asphalt and presses it with a roller. The increased surface friction also promotes safety.

- Colorless synthetic binders and light-colored aggregate - an approach common to sports venues ( $p 54)$ ".

As early as 1992, researchers have surmised that by increasing the albedo of paving materials, the overall temperature of an urban area might be decreased (Akbari et al. 1992). This hypothesis has since been well studied, using both large scale computer simulation of entire buildings or cities, and small scale studies of real materials (Taha, 1997). A study of Fresno, CA, evaluated two scenarios of cool pavement implementation, a "realistic" scenario with an albedo increase of .02, and a 'maximum' scenario with an albedo increase of .09 . The realistic scenario was found to reduce the 
City's ambient temperature by $.2{ }^{\circ} \mathrm{Kelvin}$, while the maximum scenario reduced temperatures by $.8{ }^{\circ}$ Kelvin (Taha, 2008). Despite their potential to help cool cities, cool pavements have not been widely implemented.

Cool pavements have lagged behind cool roofs in terms of policy formation and implementation, and are more often associated with negative effects. Lower adoption of cool pavements may be due to the privatized nature of the benefits of cool roofs, which lower energy demand in buildings and thus offer cost savings to the owner, as opposed to the more public benefits of cool pavements, which lower ambient temperatures and thus benefit everyone in their vicinity. In addition, the US EPA (2008) cites three other factors that may hinder cool pavement adoption:

1. Pavements are complex. Conditions that affect pavement temperatures, but not roofing materials, include: (a) dirtying and wearing a way of a surface due to daily foot and vehicle traffic, affecting pavement surface properties; (b) convection due to traffic movement over the pavement; and (c) shading caused by people and cars, vegetation, and neighboring structures and buildings.

2. Pavement temperatures are affected by radiative and thermal characteristics, unlike cool roofs, where radiative properties are the main concern.

3. Pavements serve a variety of functions throughout an urban area. Their uses range from walking trails to heavily trafficked highways (unlike cool roofs, which generally perform the same function and are off-the-shelf products). Different materials and specifications are needed for these different uses, and pavements are often individually specified, making it difficult to define or label a cool pavement ( $p 3$ ). 
While LA does not currently have a cool pavement policy or programs, the Los Angeles City Council recognized the potential for cool pavements to reduce the UHIE in 2013, when it passed a motion directing the City's Bureau of Street Services and the General Services Department to "report back on the feasibility of using alternative paving materials capable of reflecting heat from sunlight, thus reducing the heat island created by asphalt" (LA, 2013). This motion led to an interdepartmental correspondence from the Director of the Bureau of Street Services to the City Administrative Officer, identifying the most promising options for increasing street albedo: a light colored seal coat and a rubberized slurry seal. However, the light colored seal coat was found to reduce the roadway co-efficient of friction, thereby making the roadway more slippery and possibly unsafe. The light colored slurry seal was found to be the most promising option, and the Bureau of Street Services requested cost estimates from their suppliers. A slurry seal is a mixture of asphalt emulsion, water, well-graded fine aggregates and mineral fillers. Slurry seals are a preventative maintenance activity used to repair minor distress and improve skid resistance. Slurry seals are usually black, but can be made gray or tan by adding zinc oxide (Nichols Engineers, 2012, p 25).

The major barrier to the introduction of a light colored slurry was found to be the fact that the pigment used to lighten the slurry would permeate the entire factory where the slurry was produced, making it impossible for that factory to produce conventional, dark colored slurry. This could potentially increase materials costs. A second motion, passed 
in March 2014, directed the Bureau of Street Services and the Department of General Services to conduct a cost/benefit analysis of light colored paving material options.

\section{Costs of reflective pavements}

Specific cost information on cool pavements are highly project specific, due to the varying nature of the pavement treatments and local material costs and availability. The US EPA's estimated costs of various pavements are shown in table 3 (2008).

A study by Nichols Engineers (2012) found that local contractors in the Chula Vista area charged approximately $\$ .30$ per square foot for the addition of reflective color pigments and seals. This contractor also provided both conventional asphalt and light colored asphalt at the same price point, of $\$ 100$ per ton. Further, they assert that "a cool pavement option with a high UHI impact does not necessarily cost more than the conventional alternative.

For example, the use of a light colored fly ash or slag cement to replace Portland cement in a concrete pavement will increase the pavement solar reflectance and often is cost neutral or even reduces costs" (Nichols Engineers, 2012, p 1). Direct comparisons of a conventional pavement product and a 'cool' pavement product can be made between conventional concrete and white cement concrete. White cement concrete has been manufactured in a way that reduces its iron content, and thus makes it lighter in color. A statewide cost range for conventional concrete is $\$ 4$ to $\$ 6$ per 
square foot, while white cement concrete ranges from $\$ 3.40$ to $\$ 12$ per square foot (Caltrans, 2011). A coalition of LA non-profits known as the "Streets for the Future Coalition" has recommended that the City allocate $3 \%$ of road reconstruction project budgets for cool pavement treatments (Streets for the Future Coalition, 2014).

Table 3: Comparative costs of various pavements and cool pavements

\begin{tabular}{|c|c|c|c|}
\hline $\begin{array}{l}\text { Basic Pavement } \\
\text { Types }\end{array}$ & $\begin{array}{l}\text { Example cool } \\
\text { approaches }\end{array}$ & $\begin{array}{l}\text { Approximate } \\
\text { installed cost } \\
\left(\$ / \mathrm{ft}^{2}\right)\end{array}$ & \begin{tabular}{|l|} 
Estimated \\
service life \\
(years)
\end{tabular} \\
\hline \multicolumn{4}{|l|}{ New construction } \\
\hline $\begin{array}{l}\text { Asphalt } \\
\text { (conventional) }\end{array}$ & $\begin{array}{l}\text { Hot mix asphalt } \\
\text { with light } \\
\text { aggregate, if } \\
\text { locally available }\end{array}$ & $\$ .010-\$ 1.50$ & $7-20$ \\
\hline $\begin{array}{l}\text { Concrete } \\
\text { (conventional) }\end{array}$ & $\begin{array}{l}\text { Portland cement, } \\
\text { plain-jointed }\end{array}$ & $\$ 0.30-\$ 4.50$ & $15-35$ \\
\hline \multirow{3}{*}{$\begin{array}{l}\text { Nonvegetated } \\
\text { permeable } \\
\text { pavement }\end{array}$} & Porous asphalt & $\$ 2.00-\$ 2.50$ & $7-10$ \\
\hline & Pervious concrete & $\$ 5.00-\$ 6.25$ & $15-20$ \\
\hline & Paving blocks & $\$ 5.00-\$ 10.00$ & $>20$ \\
\hline $\begin{array}{l}\text { Vegetated } \\
\text { permeable } \\
\text { pavement }\end{array}$ & $\begin{array}{l}\text { Grass/gravel } \\
\text { pavers }\end{array}$ & $\$ 1.50-\$ 5.75$ & $>10$ \\
\hline \multicolumn{4}{|l|}{ Maintenance } \\
\hline \multirow[t]{3}{*}{$\begin{array}{l}\text { Surface } \\
\text { applications }\end{array}$} & $\begin{array}{l}\text { Chip seals, if } \\
\text { locally available }\end{array}$ & $\$ 0.10-\$ 0.15$ & $2-8$ \\
\hline & Microsurfacing & $\$ 0.35-\$ 0.65$ & $7-10$ \\
\hline & $\begin{array}{l}\text { Ultra-thin white } \\
\text { topping }\end{array}$ & $\$ 1.50-\$ 6.50$ & $10-15$ \\
\hline
\end{tabular}


Arguments against cool pavements

Arguments against cool pavements cite the possibility that reflective pavements will increase pedestrian discomfort (Hui, 2012), and the possibility for unintended consequences, such as reduced precipitation, and increased winter heating demand (Yang, Wang, \& Kaloush, 2014). Hui (2012) modeled the effects of reflective pavement on human thermal comfort in LA's summer and winter climate, and found that although reflective coatings reduce surface temperature of pavement, they also increase the amount of thermal radiation hitting the body of pedestrians during hot periods ( $p$ 350). The increased thermal radiation causes an increase in the perception of heat, even though actual temperatures may be lower. Pedestrians may then be discouraged from walking, and influenced to take other modes of travel.

\subsubsection{Green Infrastructure}

Green Infrastructure is a term used to describe the planting of trees, shrubs and grasses for their ecosystem services in urban areas, including streets, roofs, and parks. Green infrastructure is typically discussed as a storm water management tool, however, trees and vegetation can also be very effective in reducing the UHIE.

\section{Tree planting}

The case for "greening" cities has traditionally been made from a visual or aesthetic perspective. However, more recently, researchers have begun to quantify the many 
benefits of urban trees and green spaces. Urban trees are purported to provide many benefits, including temperature modification and energy conservation, abatement of air and water pollution, and enhanced property values (McPherson, Simpson, Xiao, \& Wu, 2008). Urban trees also provide shade and utilize photosynthesis to convert sunlight energy into sugars, which can lower the ambient temperatures around the tree. Urban parks have been found to be island of cool within a warmer sea of the built-up city, leading to the name "park cool island" (Jansson, 2007, p. 185). Bowler et al. (2010) studied a well-forested park, and found that "on average, a park was $.94^{\circ} \mathrm{C}$ cooler during the day", but concluded that "the impact of specific greening interventions on the wider urban area, and whether the effects are due to greening alone, has yet to be demonstrated". The cooling effect of trees also saves energy. Trees have been found to "reduce summer cooling and energy use in buildings at about $1 \%$ of the capital cost of avoided power plants plus air-conditioning equipment” (Rosenfeld, et al., 1995, p 255).

Tree planting and management in LA is conducted by different public and private entities, based on the location of the trees. Trees on private land are planted and maintained by the landowner, while trees on the street right-of-way are planted and maintained by the City of Los Angeles, through the Urban Forestry Division of the Bureau of Street Services. Tree planting on private land is required as part of the City's Landscape Ordinance. Guidelines C of the Landscape Ordinance (LA, 1996) requires that: 
"At least one tree, which shall not be a palm, shall be provided in the project for each 500 square feet of landscaped area in the project. A minimum of 100 square feet of unpaved area shall be provided at the base of each tree, the shortest dimension of which shall be 4 feet minimum, to allow for water infiltration and gas exchange. (b) Tree planting shall be done in the following order of priority:

(1) On the project.

(2) Off-site mitigation.

i. On private property, or along public streets (with the prior approval of the Street Tree Division, within one mile of the site of the Project.

ii. On public or private land or along public streets or the Los Angeles River anywhere within the City of Los Angeles, with the prior approval of the controlling agency, jurisdiction or owner."

The City of Los Angeles has also partnered with utility providers and non-profit organizations, such as Tree People, to assist in tree planting efforts. According to a researcher at Tree People, they use an approach called "citizen forestry", where they "work with individuals in the community who want to be leaders, and train them in a variety of different areas from volunteer coordinating, to picking the right tree, to pulling permits, to developing a maintenance plan for their planting" (personal communication, March 2014). 
Another innovative partnership organization for tree planting is City Plants, formerly known as Million Trees LA. City Plants is "a unique hybrid organization under LA's Board of Public Works with a non-profit 501(c)3 arm and foundation through Community Partners" (Cityplants.org, 2014). The new name reflects the organizations changing priorities, which are "to focus our efforts on low canopy cover areas and to plant in a way that maximizes the benefits trees provide rather than on reaching a specific number of trees" (Cityplants.org, 2014).

As part of the original Million Trees LA program, initiated under Mayor Antonio Villaraigosa in 2006, a tree canopy cover study was conducted in order to:

1) Measure existing tree canopy cover (TCC),

2) Characterize potential TCC to determine the feasibility of planting 1 million trees, and

3) Estimate future benefits from planting 1 million new trees.

The canopy cover assessment, by McPherson, Simpson, Xiao, and Wu, used "highresolution remote sensing data, aerial photographs, geographic information systems (GIS)" (McPherson et al., 2008). They found that LA has an overall canopy cover of 21 percent, with a range of 7 to 37 percent by council district (2008). This compares to "20 percent in Baltimore and 23 percent in New York City". They estimated a potential to add 2.5 million additional trees to the existing population of approximately 10.8 million, but only 1.3 million of the potential sites were deemed realistic to plant (McPherson et 
al., 2008). Figure 2 shows the results of the canopy cover assessment, listed by council district (Reproduced from McPherson et al., 2008).

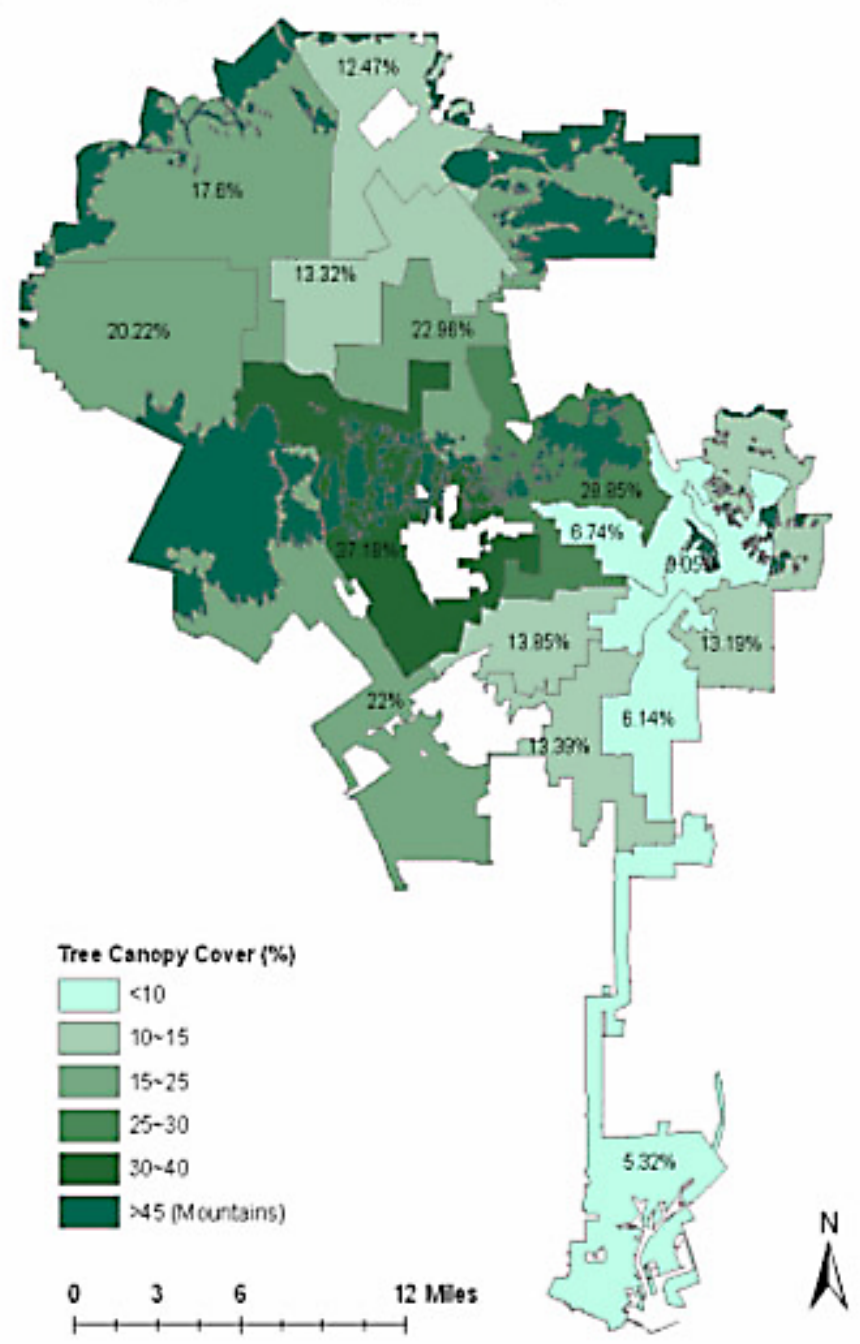

Figure 2. City of LA tree canopy cover by council district.

Another canopy cover assessment was conducted by Gillespie et al. (2011), who examined aerial photos of LA, dating back to the 1920's, in order to determine how tree canopy cover has changed over time. They found that tree densities in the Los Angeles basin have increased linearly since the 1920's, with wide variation in tree density 
between council districts. They estimated that LA "averages approximately 104 trees per hectare, based on 2006 imagery at .3 meter resolution". Spread over LA's 121,470 hectares, this rate would equate to $12,632,880$ trees, about $16 \%$ greater than McPherson et al.'s estimate of 10.8 million.

Two cities that have implemented extensive urban greening programs are Hong Kong and Sacramento, CA. Hong Kong is an extremely high-density urban area, which was built without consideration for green spaces within the city ( $\mathrm{Ng}$ et al., 2012). However, starting in 1999, the Hong Kong special administrative region (SAR) government embarked on an ambitious plan to make Hong Kong a "green model for Asia", which has resulted in the planting of over 100 million trees. $\mathrm{Ng}$ et al. (2012) examined various urban greening strategies in Hong Kong, in order to determine which strategies were the most effective at lowering ambient air temperatures. They found that "roof greening is ineffective for human thermal comfort near the ground. Trees are also suggested to be more effective than grass surfaces in cooling pedestrian areas. The amount of tree planting needed to lower pedestrians level air temperature by around $1^{\circ} \mathrm{C}$ is approximately $33 \%$ of the urban area" (p. 256). Sacramento, CA presents a domestic example of large scale tree planting.

Sacramento, CA has long valued its urban forest, and has had an active urban tree planting program since the 1920's. Simpson (1998) studied 71 county subdivisions in Sacramento, analyzing the tree density, canopy cover, building size and age. Simpson 
found annual cooling savings due to the urban forest of approximately 157 gigawatt hours (GWh), valued at $\$ 18.5$ million dollars per year. In total, Simpson (1998) found that Sacramento's urban forest saves approximately \$20 million through combined shade, air-temperature, and wind-speed effects on annual heating and cooling, with an average maximum air-temperature reduction of $2.3^{\circ} \mathrm{C}$ (p. 203).

\section{Costs of tree planting}

The costs of tree planting in LA vary widely, depending on who is doing the planting. The initial cost of tree planting includes various cost components, such as: the tree sapling itself, delivery, labor, soil conditioner, fertilizer, mulch, and initial watering. Ongoing costs associated with trees include watering, maintenance, and supplemental fertilizer.

Residents of LA have several sources from which to receive low-cost or free trees. The non-profit Tree People, for example, will plant trees for a mere \$25 for one tree (Treepeople, 2014). However, this cost is highly subsidized. Several City of Los Angeles Departments also offer free tree planting. The LA Department of Environmental Services will plant a tree, upon request, in the public right-of-way in front of a home or business, on the condition that the requestor maintains the tree. Although this service is free to the requestor, there are internal costs to the Department that total approximately $\$ 200$ per tree (City of Los Angeles, personal correspondence, November 4, 2014). However, this only includes the initial cost of planting. 
Pincetly, Gillespie, Pataki, Saatchi and Sapores (2012) evaluated the water use of street trees in LA. They found that if the urban forest was composed entirely of high water use species, their water demand would consume up to $62 \%$ of municipal water use, and if the urban forest was entirely low water use species, they would consume only $9 \%$ of municipal water. The actual value is somewhere in between, and depends on the current species composition (Pincetl et al., 2012, p 8).

\section{Arguments against tree planting}

Arguments against tree planting in LA center on water use, and the inappropriateness of trees in a semi-arid, desert-like climate. Miller (2011), argues that increased tree planting would lead to greater use of imported water from Northern California, which is threatened due to environmental restrictions on water draw down from rivers and streams. Miller also argues that tree planting efforts are not appropriate to LA's climate, and are a result of imperial migrants "americanizing Southern California" (2011).

\section{Living roofs}

Another strategy for increasing vegetative surfaces in urban areas is the installation of 'living roofs', also called 'green roofs'. Living roofs incorporate soil and vegetation into the structure of the roof. There are a number of different living roof technologies, but most living roofs can be classified as 'intensive', 'semi-intensive' or 'extensive', based on the depth of their soil profile, which typically ranges from 2 inches to 15 inches. 
Living roofs become popular in the US as a result of the green building movement, but they trace their modern roots to Germany (where they have been popular since the 1970's) and their ancient roots to Scandinavia (where sod roofs were used for insulation).

Living roofs have been shown to produce multiple benefits, including: moderating the temperature of the building they cover, reducing mechanical cooling demand, absorbing and slowing storm water runoff, providing wildlife habitat, reducing air pollution, reducing the urban heat island effect, increasing the life of building's waterproofing membrane, and providing aesthetic enjoyment. On hot days, living roofs can reduce the surface temperature of a roof significantly. The US EPA found that, on a $90^{\circ} \mathrm{F}$ August afternoon, the living roof on Chicago's City Hall was 40 to $80^{\circ} \mathrm{F}$ cooler than an adjacent, conventional roof (2008). Living roofs have also been shown to "reduce peak storm water runoff rates by $65 \%$, and extend by three hours the time it takes for water to leave a site" (Sproul, Wan, Mandel \& Rosenfeld, 2014).

Some of the temperature reduction and storm water absorption benefits of living roofs are a function of the plants themselves. The plants utilize storm water, while also providing cooling as a result of leaf shading and evapotranspiration. Evapotranspiration is a process by which leaves allow water, drawn up from their roots, to evaporate through the opening of their stomata. This evaporation is necessary for the plant to complete photosynthesis. As a result of this process, "heat energy is then drawn from 
the surrounding air to convert that water to water vapor, which produces a cooling effect" (City of LA, p II-1, 2006). The remainder of the storm water and cooling benefits of living roofs are a result of the soil layer, which both absorbs storm water and acts as insulation.

Roofs represent $18 \%$ of the surface area of $L A$, and can reach up to $32 \%$ in some areas (Oberdorfer et al., 2007). Roofs play a large role in the indoor and outdoor temperature of urban areas, as well as the hydrology. Traditional rooftops are completely impervious, and shed all storm water directly to the City's storm water drainage system. During periods of intense rain, storm water drainage systems can be overwhelmed, especially in older cities with combined storm and sewer systems. When these combined storm and sewer systems are overwhelmed, they must dump diluted but untreated sewage into surrounding water bodies. From 2003 to 2008, LA was one of the largest recipients of EPA fines related to combined sewer overflows, totaling $\$ 1.6$ million dollars (Wheeler, 2008). According to the US EPA, each year "combined sewer systems discharge an estimated 850 billion gallons of storm water mixed with untreated sewage into local waters" (Wheeler, 2008).

Los Angeles does not have a living roof requirement, but the City's Environmental Affairs Department published a resource guide to living roofs in 2006, titled "Green Roofs- Cooling Los Angeles". This guide was prepared "in partial response to Los Angeles City Council motion CF\#04-0074, Incorporate Rooftop Green Spaces as an 
Energy Efficiency Mechanism. This motion directed the Environmental Affairs Department to lead the formation of a City task force for the purpose of developing and implementing "a process, program, or procedure that will require City facilities to incorporate rooftop green spaces as an energy efficiency mechanism" (City of LA, 2006).

\section{Costs of living roofs}

Living roofs have significantly higher initial costs than conventional roofs, averaging approximately $\$ 15$ per square foot (sq. ft.) installed nationally, compared to $\$ 5.30$ to $\$ 6.86$ per sq. $\mathrm{ft}$. installed for a shingle roof and $\$ 6$ to $\$ 10$ per sq. $\mathrm{ft}$. for a flat EPDM membrane roof in LA (homewyse, n.d.). However, some studies have shown living roofs to be more environmentally friendly than traditional roofs, over the course of their lifetime. Kosareo and Ries (2006) analyzed a conventional roof, an extensive living roof and an intensive living roof using "life cycle assessment", which takes into account "the environmental impacts of the fabrication, transportation, installation, operation, maintenance, and disposal" of a given product (Kosareo \& Ries, 2006, p. 2,606). They found that the extensive living roof had about one-half of the impact of the control roof, while the intensive living roof had slightly less impact than the control roof (Kosareo \& Ries, 2006). However, the results of cost effectiveness studies on living roofs have been more mixed, and largely depend on the incentives offered by local municipalities. 
Sproul, Wan, and Mandel (2014) conducted a life-cycle cost analysis of living roofs, cool roofs, and conventional roofs. They found that, relative to typical dark colored roofs, living roofs have a negative 50 year net savings of $\$ 6.60$ per square foot. Cool roofs, by contrast, had a positive net savings of $\$ 2.40$ per square foot. However, they contend that the annualized net cost difference between living roofs and cool roofs is so small (\$.30 per square foot) that the choice between a living roof and a cool roof should be based "on the preferences of the building owner". Owners concerned with local environmental concerns were encouraged to choose living roofs, while owners concerned with global warming should choose cool roofs (Sproul et al., 2014).

In cities that charge a storm water fee based on impervious surface area, living roofs can pay for themselves exclusively through their storm water absorption. These cities are primarily in the north east of the country, and include Washington D.C. and Philadelphia. Washington D.C. combines a living roof incentive of up to $\$ 10$ per square foot with a reduction in storm water fees. This has provided a powerful financial incentive to building owners which has led to more living roof installations than anywhere else in the country.

Green roofs also carry higher maintenance costs than conventional roofs. Green roofs require weeding, watering, occasional fertilization, and occasional replacement of plants, especially during the first two years. During this period, "at least two laborers are required to perform a minimum of three visits per year" (Sproul et al., 2014). These 
activities add up to an average annual maintenance cost of $\$ .27-\$ 1.50$ per square foot (US EPA, Green Roofs, n.d.; Sproul, et al., 2014). Conventional roofs also require maintenance, which typically consists of power washing to remove accumulated debris, the repair or punctures or leaks, and the cleaning of gutters.

\section{Arguments against living roofs}

Arguments against living roofs center on their cost and inappropriateness to LA's semiarid climate. Some cities that have enacted mandatory living roof legislation have experience backlash from the business community, or from schools. Toronto enacted a living roof bylaw (ordinance) in 2009 which required high rise office and residential buildings to include living roofs, and tried to enact another bylaw in 2011 which would have included schools and industrial buildings. However, the City government felt a strong backlash from this potential mandate from schools and industry who thought it would be too expensive to comply with. A coordinator of capital services for a Catholic school board indicated that "It's a major portion of work and we have enough trouble keeping the grass green on the ground, let alone the roof" (Alcoba, 2011). Industrial concerns argued that the requirement would be too expensive, and lobbied for an alternative requirement for cool roofs instead. By 2012, the final requirement for industrial buildings was reduced to $10 \%$ of available roof surface, with an alternative for $100 \%$ cool roofing materials and other on-site storm water management practices. 
The argument that living roofs are inappropriate to LA's climate has much to do with rainfall, or lack thereof. The cities of the US with well-developed living roof policies and industries tend to be located in high rainfall areas. The number one living roof city in terms of installed square footage is Washington D.C., which receives 49.75 inches of rain per year (NOAA, 2014). The number two city, Chicago, received 39.09 inches per year (NOAA, 2014). By contrast, LA receives less than half of this amount, at only about 15.14 inches per year. During the ongoing drought that began in 2012, LA has received only 11.12 inches total (NOAA, 2014). In the absence of natural rainfall, living roof plants must be irrigated, in order to avoid losing the plants to desiccation. While the majority of living roof plants used in LA are expected to be highly drought tolerant, they still require occasional irrigation throughout the dry season. In a city with limited water resources, this is a legitimate concern.

\subsubsection{Solarization}

Solar photovoltaic panels convert energy from sunlight into electricity. Recently, the installation of solar panels has accelerated as prices have dropped. Large-scale deployment of solar panels has been studied as a way to simultaneously mitigate the UHIE and provide renewable electricity. Solar panel deployment is heavily dependent on the incentives and rebates offered by local utilities and state governments. 
Clean LA Solar is a "feed-in tariff" program run by Los Angeles Department of Water and Power (LA DWP), in which solar panel owners are allowed to sell back excess power generation to the utility. Prior to this program, solar panel owners were not allowed to sell excess back into the grid, and were only able to offset their own power generation. Clean LA Solar creates an incentive for owners of large roofs, such as warehouses and manufacturers, to install large-scale solar arrays.

In 2011, the California Energy Commission commissioned a study entitled "Air Quality Impacts of Heat Island Control and Atmospheric Effects of Urban Solar Photovoltaic Arrays" (Taha, 2011). This study examines the potential impact on the UHIE of the large-scale installation of solar photovoltaic panels. The study examined LA in detail, because it has a very large potential for rooftop solar deployment. They estimated that the LA basin could potentially deploy between 71 and 137 square kilometers of solar panels. They found that the net effect of a high deployment of solar panels on ambient temperatures depends largely on the energy conversion efficiency of the panels. Solar photovoltaic panels are able to convert a certain percentage of the light that hits them into electricity. In 2013 , most panels newly installed panels converted about $15 \%$ to $16 \%$ of the light energy that hit them, into electricity. The study's model included assumptions of panels with efficiencies of 10, 15, 20, 25 and 30 percent, as efficiencies are expected to increase steadily over time. Taha (2011) found that at low efficiencies (10\%), large scale deployment of solar panels would have virtually no cooling impact on regional temperatures, and could actually slightly increase average temperatures. At $20 \%$ 
efficiency, "some cooling could be detected", but the cooling is only about $.09^{\circ} \mathrm{F}$. However, at $30 \%$ efficiency, regional cooling could be up to $.27^{\circ} \mathrm{F}$.

\section{Costs of solar panels}

The costs of solar panels have dropped steadily since their introduction in the 1970's. In the second quarter of 2014, average solar energy costs in California were approximately \$5 per watt, including installation, down from \$10.50 per watt in 2007 (Go Solar California, 2014).

\section{Arguments against solar panels}

Arguments against solar panels focus on their cost, the subsidies they receive, and the potential for homeowners with solar panels to avoid paying for the cost of energy transmission.

In most of the country, producing electricity from solar panels is more expensive than other energy sources. The price of solar energy is 12 to 30 cents per kilowatt-hour, versus 10 cents for coal and 8 cents for natural gas (Goodrich, James, \& Woodhouse, 2012). The price of solar is dropping however, and costs vary by region, and in some states, such as Hawaii, solar energy is already the cheapest source of energy. Cost to the consumer are usually only cost-competitive due to government financial incentives. 
In most states, residential solar installations are eligible for tax rebates or utility incentives. However, as Swan (2014) points out, "there is inherent unfairness in these subsidies which are only available to relatively wealthy single-family home owners. People living in multi-family dwellings, renters, and those on low or fixed incomes that cannot afford the capital costs of the installation cannot share in these programs".

Solar power has also come under attack from utilities, who argue that so-called "netmetering" policies allow solar panel owners to avoid the costs of electricity transmission. Net-metering allows solar households to run their meter backwards when they are producing more electricity than they are producing (Than, 2013). Net-metered solar customers are able to significantly reduce or even eliminate their electricity bills, even though they are connected to, and dependent on, the electricity grid. Utilities allege that this leads to less revenue and less customers to pay for upkeep of the electricity grid (Than, 2013). Utilities have attempted to challenge statewide net-metering polices, including in California, with some success (John, 2013).

\subsection{Climate Change Adaptation}

According to Ireland (2012), "the concept of climate change adaptation emerged in the literature around 30 years ago and has since received increasing attention" ( $p$ 93). The International Panel on Climate Change (IPCC) defines climate change adaptation as "adjustments in natural or human systems in response to actual or expected climatic 
stimuli or their effects, which moderates harm and exploits beneficial opportunities". Climate change adaptation is often confused with climate mitigation, which consists of "policies that control the emissions of pollutants that affect climate change" (IPCC, 2014). In California, climate change mitigation efforts were mandated by the passage of Assembly Bill 32 (AB 32), the "Global Warming Solutions Act of 2006", which requires a sharp reduction of GHG emissions.

Assembly Bill 32 requires the State Air Resources Board (CARB) to adopt a statewide emissions limit equivalent to 1990 levels by the year 2020 (Global Warming Solutions Act, 2006). Local governments are required to comply with statewide emissions targets, when writing their general plans, by inventorying GHG emissions within their boundaries and developing programs and policies to reduce emissions. Local governments can also proactively comply with $A B 32$ by writing 'climate action plans' (CAPs), which are "comprehensive roadmaps that outline the specific activities that an agency will undertake to reduce greenhouse gas emissions" ('climate action plans', n.d.). Los Angeles's CAP, issued in 2007, is titled "Green LA: An Action Plan to Lead the Nation in Fighting Global Warming". The CAP "covers $\mathrm{CO}_{2}$ emissions from public and private activities within the City of LA. It addresses emissions from major sources of $\mathrm{CO}_{2}$, including the production and consumption of electricity, transportation fuel and natural gas. The plan presents mitigation and adaptation actions to reduce $\mathrm{CO}_{2}$ emissions" (Green LA, 2007, p. 10). While the majority of the plan focuses on actions to reduce $\mathrm{CO}_{2}$ emissions, it does contain a focus area that describes climate adaptation efforts, 
with the goal to "climate proof Los Angeles". The actions identified to achieve this goal include:

- Improve capacity to respond to climate-related emergencies through education and outreach;

- Develop comprehensive plans to prepare for climate change impacts affecting LA, including increased drought, wildfires, sea level rise, and public health impacts;

- Review current zoning and building codes to minimize climate change impact; and

- Reduce the heat island effect by planting 1 million trees throughout the city and increasing open space" (Green LA, p 26, 2007).

The IPCC differentiates climate change adaptation into three types: anticipatory, autonomous and planned. Anticipatory adaptation is defined as "adaptation that takes place before impacts of climate change are observed". Autonomous adaptation is defined as "adaptation that does not constitute a conscious response to climatic stimuli, but is triggered by ecological changes in natural systems and by market or welfare changes in human systems. Planned adaptation is defined as "adaptation that is the result of a deliberate policy decisions, based on an awareness that conditions have changed or are about to change and that action is required to return to, maintain, or achieve a desired state" (IPCC, 2007). While autonomous adaptation is expected to 
occur in LA, this study focuses on anticipatory, planned adaptation, or more specifically, the steps that LA can take to plan for adapting to hazard of future increases in heat.

Climate change adaptation shares much in common with the older concept of natural hazard mitigation, which is defined by the Code of Federal Regulations as "any action taken to reduce or eliminate the long-term risk to human life and property from natural disasters". According to this definition, climate change adaptation strategies are also a form of hazard mitigation. The California Emergency Management Agency lists four options for hazard mitigation activities and projects:

1) Land use planning and regulation of development in hazard zones, such as floodplains and wild land-urban interface areas,

2) Development and enforcement of building codes,

3) Retrofitting structures, and

4) Removing structures from hazardous areas" (CalEMA, n.d.).

These suggested hazard mitigation activities seem to serve as programs which support the goals of climate change adaptation.

The most recent IPCC report (2014) states that "the framing of adaptation has moved further from a focus on biophysical vulnerability to the wider social and economic drivers of vulnerability and people's ability to respond" ( $p$ 836). However, the focus of climate change adaptation may vary between countries. For example, developing countries are seen as more susceptible to the impacts of climate change, due to a lack of financial 
resources and infrastructure. Therefore, actions taken in developing countries for the purpose of climate change adaptation can range from "climate proofing" infrastructure, to poverty alleviation (Ireland, 2012). In the United States, climate adaptation tends to focus on research, planning, and public health, while hazard mitigation tends to focus on infrastructure and inter-agency coordination. The California Climate adaptation Plan (2009), lists the following five strategies for climate change adaption:

1) Promote comprehensive state agency adaptation planning,

2) Integrate land use planning and climate adaptation planning,

3) Improve emergency preparedness and response capacity for climate change impacts, and

4) Expand California's climate change research and science programs and expand public outreach of research to policy-makers and general public.

Together, natural hazard mitigation and climate change adaptation form a complementary planning and regulatory framework for addressing the impacts of extreme heat, which is both a natural hazard and a result of climate change. So far, climate change adaptation has focused on understand the potential impacts of climate change, long-term planning and preparation for a myriad of climate change impacts, while natural hazard mitigation has focused on specific regulatory tools and actions that can be taken to mitigate impacts. Now that there is a good understanding of both the impacts of climate change in LA and the effectiveness of potential mitigation strategies, 
increasing heat should be seen as a natural hazard which can be addressed at the local and regional level through proactive regulation of the built environment.

\subsection{Gaps in Existing Literature}

The analysis of existing literature focused on the fields of climate change, urban design, urban climatology and climate change adaptation.

The analysis identified several gaps in knowledge that may not have been adequately studied. While the effects of individual urban design strategies for climate change adaptation have been well studied, little attention has been paid to the cost effectiveness of those strategies. The City's current climate action plan mentions goals for the mitigation of GHGs, but omits any specific climate adaption goals, and how to achieve them. The urban climatology field produces ever more accurate models to predict the interaction between the built environment and climate. However, it is typically left to elected representatives to turn this scientific data into policy. This gap between science and action leaves a role for the planner to interpret the findings of urban climatology, weigh the costs and benefits of various proposals, and recommend how, and at what rate, they should be implemented. The four gaps in existing literature and planning include:

1) The political and social implications of various climate mitigation strategies. 
The political and social acceptance of large scale implementation of climate mitigation strategies is not considered in existing literature. However, the potential for backlash is real. Arguments have been made against cool roofs (as ugly), tree planting (they use too much water), living roofs (too expensive and use too much water), and reflective surfaces (they have unintended consequences).

2) The cost-effectiveness of climate mitigation strategies.

Existing studies on the effectiveness of various mitigation strategies, such as Taha (2013) fail to take into account the costs of implementation. Cost can be expected for both the City government (to set-up and administer policies or programs), and the private sector (for installation and maintenance). An understanding of costs, specific to $L A$, is essential to the prioritization of various strategies based on their costeffectiveness.

3) Best practices for implementing climate adaptation policies

Little research has been done on how to best implement climate adaptation policies, and how to effectively integrate climate change mitigation strategies into a City's existing regulatory framework. 


\section{RESEARCH QUESTIONS AND RATIONALE}

The three research and policy gaps indicate that there is a need to better understand the cost-effectiveness of various climate adaptation strategies, how politically and socially acceptable they are, and how they might be most effectively implemented.

\subsection{Research Questions}

\subsubsection{Research Question 1}

What urban design policies are most cost-effective for reducing temperatures in LA? Knowledge of the cost-effectiveness of various urban design strategies is essential in an environment of limited municipal resources. Los Angeles should prioritize climate adaptation strategies that are both effective and cost effective. This question will be explored using method 1: cost-effectiveness analysis.

\subsubsection{Research Question 2}

How politically and socially acceptable are climate adaptation strategies?

The local political and social realities of LA will dictate how aggressively certain mitigation measures can be implemented. Knowledge of the political acceptability of various strategies will help to determine which strategies may prove difficult to implement. This question will be answered using method 2: key stakeholder interviews, in which interviewees will be asked to rate the political acceptability of each strategy. 


\subsubsection{Research Question 3}

How can climate adaptation policies best be implemented?

Other cities have implemented similar mitigation measures to those explored in this paper. The experiences of these cities can serve as lessons for how to effectively develop and implement them. This question will be answered using method 3: case studies.

\subsection{Methods}

The methods used to answer the research questions are shown in table 4.

Table 4. Research methods

\begin{tabular}{|l|l|l|}
\hline Question & Method & Unit of measure \\
\hline $\begin{array}{l}\text { 1. Which climate adaptation } \\
\text { policies are most cost- } \\
\text { effective for reducing } \\
\text { temperatures in LA? }\end{array}$ & $\begin{array}{l}\text { 1. Cost-effectiveness } \\
\text { analysis }\end{array}$ & $\begin{array}{l}\text { Million dollars/ degree } \\
\text { of cooling }\end{array}$ \\
\hline $\begin{array}{l}\text { 2. How politically and socially } \\
\text { acceptable are climate } \\
\text { adaptation strategies? }\end{array}$ & $\begin{array}{l}\text { 2. Key stakeholder } \\
\text { interviews }\end{array}$ & $\begin{array}{l}\text { High, Medium, or Low } \\
\text { political feasibility }\end{array}$ \\
\hline $\begin{array}{l}\text { 3. How can climate adaptation } \\
\text { policies best be } \\
\text { implemented? }\end{array}$ & 3. Case studies & \\
\hline
\end{tabular}

\subsubsection{Cost-effectiveness Analysis}

The four mitigation strategies are compared using according to their cooling effectiveness and cost, in order to derive a rough measure of cost-effectiveness. 
Cooling effectiveness will be determined through a review of existing literature. Cost will be determined through published cost data and personal interviews.

Cost effectiveness analysis is defined as "a form of economic analysis that compares the relative costs and outcomes of two or more courses of action". Cost effectiveness analysis is different than cost benefit analysis in that it measures the incremental cost per unit of cooling benefit, rather than attempting to measure the net benefit of implementing various mitigation measures in terms of dollars. Therefore, the resulting unit of this cost effectiveness will be millions of dollars per degree of cooling benefit. It is assumed that all of the mitigation strategies will be fully implemented by the year 2050 .

\subsubsection{Interviews}

Interviews were conducted with four key stakeholders representing various governmental and non-governmental agencies. These interviews provided background information, as well as qualitative understanding of the political and regulatory framework around climate change adaptation in LA. Interview questions were presented to interviewees prior to the interview, but an open ended interview form was also used, as interviewees were encouraged to elaborate on any questions. Interview topics included: a ranking of the political acceptability of UHIMSs, overall efforts to adapt to climate change, the most effective UHIMS, barriers to implementing UHIMSs, and possible regulatory incentives for UHIMS. 
Interview 1 was conducted on March 13, 2014 with a high level director at the Los Angeles Department of Power and Water (DPW). Interview 2 was conducted on March 17, 2014 with the Research Director of a LA-based non-profit organization that plants trees. Interview 3 was conducted on March 20, 2014 with a high level director at the Los Angeles Urban Design Studio. Interview 4 was conducted on March 28, 2014 with a City Planning Associate with the City of Los Angeles. These interviews were conducted in order to answer research question two.

\subsubsection{Case Studies}

Detailed case studies of climate adaptation policies in other cities are used in order to determine:

1. The experiences of other cities in climate adaptation and

2. Implementation progress (how has the legislation worked so far?). 


\section{$4 \quad$ FINDINGS}

\subsection{Cost Effectiveness Analysis}

The purpose of the cost effectiveness analysis is to rank each UHIMS by the degrees of cooling that it produces per dollar. This analysis is not intended to be a detailed projection of the total costs of implementing each HIMS, but rather a very rough approximation of costs sufficient to prioritize HIMS for further study. This analysis does not take into account complex economic factors, such as the change in unit cost as units increase, or the time value of money. In addition, this analysis does not take into account the financial benefits of HIMS. Some HIMS, such as solar panels and cool roofs, are installed primarily by private parties in order to generate electricity or reduce cooling costs. Other HIMS, such as trees and cool roofs, are implemented by the public sector in order to provide public benefits. The benefits of HIMS are more difficult to quantify than the costs, and were determined to be outside the scope of a costeffectiveness analysis.

In order to determine the cost-effectiveness of each UHIMS, a four-step process was used. The first step was to determine the existing conditions and land cover of LA, such as the total extent of rooftops, the tree canopy cover, the total extent of solar panels, and the extent of streets and highways. The second step was to determine the unit costs of implementing UHIMS, such as the cost of a single tree, solar panel, or square foot of "cool" rooftop coating. The third step was to determine feasible scenarios for 
implementing each UHIMS. This involved, for example, determining how much the tree canopy can realistically be increased, and what percentage of rooftops can be converted to "cool" roofs. The final step was to determine the relative cooling effectiveness derived from those UHIE measures, by dividing the total cost by the total cooling effectiveness.

\subsubsection{Existing Conditions}

This section summarizes the existing land cover conditions of LA, relating to rooftops, trees, streets and roads, solar panels and green roofs. These existing conditions serve as the baseline from which modifications to the built environment can be assessed. Data from various sources is compared to the primary data source, which is Taha (2014). Taha's climate model uses land cover data provided by the United States Geological Survey (USGS).

\section{Rooftops}

According to Weiss, Woods and Levinson (2014), LA has $1,130,120$ rooftops, with a total roof area of $222.4 \mathrm{~km}^{2}\left(85.86 \mathrm{mi}^{2}\right)$ and a mean roof albedo of $.17+$ or -.08 . However, Taha (2014) estimated that LA has a total rooftop area of approximately 33 square miles, which equals only $85.45 \mathrm{~km}^{2}$. Weiss et al.'s estimate was used as the rooftop total, rather than Taha's, as it was based on actual aerial photographs rather than estimated land cover. As shown in table 8 , the total fraction of the city covered by 
roofs was determined to be $18.3 \%$. Taha's (2014) cool roof implementation scenario calls for increasing the mean rooftop albedo, as shown in table 6.

Table 6: Rooftop coverage by land use type

\begin{tabular}{|l|l|l|l|l|l|}
\hline Land use type & $\begin{array}{l}\text { Current } \\
\text { albedo }\end{array}$ & $\begin{array}{l}\text { Albedo } \\
\text { increase }\end{array}$ & $\begin{array}{l}\text { Resulting } \\
\text { albedo }\end{array}$ & $\begin{array}{l}\text { Fraction of } \\
\text { area } \\
\text { covered by } \\
\text { roofs }\end{array}$ & $\begin{array}{l}\text { Fraction of } \\
\text { entire city (\%) }\end{array}$ \\
\hline Residential & .2 & .35 & .55 & .2 & 21.6 \\
\hline Commercial & .2 & .4 & .6 & .23 & 5.6 \\
\hline Industrial & .2 & .4 & .4 & .19 & 3.3 \\
\hline $\begin{array}{l}\text { Transportation } \\
\text { and } \\
\text { communication }\end{array}$ & .2 & & & .12 & 1.5 \\
\hline $\begin{array}{l}\text { Industrial and } \\
\text { commercial }\end{array}$ & .2 & .4 & .6 & .22 & .1 \\
\hline Mixed urban & .2 & .35 & .55 & .23 & .3 \\
\hline
\end{tabular}

\section{Trees}

McPherson et al. found that LA has an overall canopy cover of 21 percent, with a range of 7 to 37 percent by council district, and estimated a potential to add 2.5 million additional trees to the existing population of approximately 10.8 million (2008). Using the LULC values provided by the USGS yields a total tree canopy area of 20.05 square miles, within the urbanized area of LA, not including open space and parks. Existing tree canopy coverage data is summarized in table 8 . 
Streets and roads

The Los Angeles Bureau of Street Services estimates that LA contains 6,500 centerline miles of roadways (2014). It is assumed that these roads have an average of 2.5 lanes at 12 foot widths. This total roadway area would therefore be 36.93 square miles, or $7.9 \%$ of the total surface area of the City. Data on the total freeway mileage in LA was not available; however, Los Angeles County has approximately 869 miles of State Highways. We can then assign a proportion of the County's total freeway miles to LA City, and assume that 107 miles are within the City of LA. For the purposes of this analysis, it was assumed that local arterial streets are made of asphalt, and highways are made of concrete. Calculations to determine the existing coverage of roadways and highways are shown in table 7.

Table 7: Existing coverage of streets and highways

\begin{tabular}{|l|l|l|l|l|l|}
\hline $\begin{array}{l}\text { Roadway } \\
\text { type }\end{array}$ & $\begin{array}{l}\text { Total length } \\
(\mathbf{m i} .)\end{array}$ & $\begin{array}{l}\text { Average } \\
\text { number of } \\
\text { lanes }\end{array}$ & $\begin{array}{l}\text { Average } \\
\text { lane width } \\
\text { (ft.) }\end{array}$ & $\begin{array}{l}\text { Total area } \\
\text { (mi. }^{2} \text { ) }\end{array}$ & $\begin{array}{l}\text { Fraction of } \\
\text { City }\end{array}$ \\
\hline $\begin{array}{l}\text { Local } \\
\text { roadway }\end{array}$ & 6,500 & 2.5 & 12 & 36.9 & $7.9 \%$ \\
\hline Highways & 107 & 6 & 15 & 1.82 & $.4 \%$ \\
\hline Total & 6,607 & & & 38.75 & $8.3 \%$ \\
\hline
\end{tabular}

\section{Solar panels}

The cumulative capacity of solar panels in LA, as of 2014, was 132 Megawatts (MW) (Sargent, Burr, Dutziak, \& Schneider, 2014). The average capacity of installed solar PV systems in LA is 12.12 Kilowatts; therefore we can assume a total of 10,891 
installations (Go solar California, 2014). The average rating of solar panels is around 200 watts $(.2 \mathrm{kWh})$, with an average size of about 16 square feet. Therefore, the average installation would use 60 solar panels, covering approximately 970 square feet. The total area of solar panels is approximately $.081 \%$ of the City, as shown in table 8 .

\section{Green roofs}

Los Angeles does not have a large number of installed green roofs. The City contains a handful of green roofs, however no data on the total extent of green roofs in LA was found.

Table 8: Existing conditions summary

\begin{tabular}{|l|l|l|l|}
\hline Land cover & Total number & Total area $\mathbf{( m i}^{2} \mathbf{)}$ & Fraction of City \\
\hline Roofs & $1,130,120$ roofs & 85.86 & $18.3 \%$ \\
\hline Trees & $10,800,000$ trees & $20.05-82.02$ & $17.5-21 \%$ \\
\hline $\begin{array}{l}\text { Streets and } \\
\text { highways }\end{array}$ & 6,607 miles & 38.75 & $8.3 \%$ \\
\hline $\begin{array}{l}\text { Solar } \\
\text { panels }\end{array}$ & 132 Mega Watts & .378 & $.081 \%$ \\
\hline
\end{tabular}

Summary

Based on the sources cited above, and given a total area of 468.67 square miles for the City of LA (US Census, 2010), the existing land cover of LA is summarized in table 9. Sources differed in their characterization of land cover in LA, possibly as a result of differing methods. Los Angeles's vast area means that even small discrepancies in 
sampling or data collection methods will be magnified through repetition. Data from Taha (2014) was used for the cost effectiveness analysis, rather than other sources, because Taha's conclusions about cooling effectiveness derive directly from assumptions about the physical nature of LA, using USGS land use and land cover data. Other sources for cooling effectiveness for all of the UHIMS in conjunction with each other were not available at the time of the analysis.

Table 9: Los Angeles land cover data summary

\begin{tabular}{|l|l|l|}
\hline Land Cover & $\begin{array}{l}\text { Total area }\left(\mathbf{m i}^{2}\right) \text { from Taha } \\
(\mathbf{2 0 1 4 )}\end{array}$ & $\begin{array}{l}\text { Total area }\left(\mathbf{m i}^{2}{ }^{2}\right) \text {, other } \\
\text { sources }\end{array}$ \\
\hline Roofs & 30.75 & $85.86^{1}$ \\
\hline Trees & 20.05 & $82.02^{2}$ \\
\hline Streets & 20.05 & $36.9^{3}$ \\
\hline Highways & NA & $1.82^{4}$ \\
\hline Solar panels & NA & $.378^{5}$ \\
\hline Total & 70.85 & 206.98 \\
\hline $\begin{array}{l}\text { Sources: } \\
\text { 1. Weiss, Woods and Levinson, 2014 } \\
\text { 2. McPherson et al., 2008 } \\
\text { 3. Los Angeles Bureau of Street Service, 2014 } \\
\text { 4. Los Angeles County } \\
\text { 5. Sargent, Burr, Dutziak, \& Schneider, 2014 }\end{array}$ \\
\hline
\end{tabular}

The remaining land cover may be comprised of a range of land cover types not listed here, such as parking lots, parks, open space, and private land not covered by trees, such as back yards and front yards. Parking lots are classified as "other" in the USGS 
land use and land cover data. However, some sources indicated that parking might cover a significant percentage of the land in LA's central business district (CBD). Manville and Shoupe (2004) state "if you took all of the parking spaces in the Los Angeles CBD and spread them horizontally in a surface lot, they would cover 81 percent of the CBD's land area". While much of the parking in LA's CBD is located in below or above ground garages, there is also an abundance of surface level parking lots which are sure to be paved, and will probably have similar impacts to the UHIE as highways and streets. Parking lots are not included in the cost effectiveness analysis, due to lack of data, but will be discussed in section 5.1 .

\subsubsection{Cooling Effectiveness}

The primary source for cooling effectiveness data is "Ranking and prioritizing the deployment of community-scale energy measures based on their indirect effects in California's climate zones" by Taha, H. (2013). The cooling effects of various UHIMSs in LA, according to Taha, are shown in table 11. 
Table 10: Cooling effectiveness of UHIMSs in Los Angeles

\begin{tabular}{|l|l|l|}
\hline $\begin{array}{l}\text { Mitigation } \\
\text { measure }\end{array}$ & $\begin{array}{l}\text { Daytime temperature } \\
\text { change (Celsius) }\end{array}$ & $\begin{array}{l}\text { Cumulative temperature change } \\
\text { (Celsius) }\end{array}$ \\
\hline Roof albedo & -0.73 & -0.73 \\
\hline Cool pavements & -0.46 & -1.19 \\
\hline Vegetation & -0.23 & -1.42 \\
\hline Cover increase & -0.31 & -1.73 \\
\hline Solar PV & -0.04 & -1.77 \\
\hline Green roofs & 0 & -1.77 \\
\hline Source: Taha, 2013 & & \\
\hline
\end{tabular}

\subsubsection{Cost}

This section summarizes the total costs of implementing cool roofs, tree planting, solar panels, reflective pavements and green roofs on a city-wide scale. Unit costs are assumed to remain constant regardless of quantity, time, changes in technology and other factors. In reality, this is unlikely, as economies of scale tend to reduce unit costs as quantities rise. Conversely, costs of installation may rise over time, if the easiest-to implement measures are installed first. However, the detailed economic models required to predict the change in price over time, or as quantities increase, are outside the scope of this paper and the expertise of its author. This cost effectiveness analysis was conducted primarily to rank the UHIMS, rather than for budgeting or cost estimation. In addition, the total cost of fully implementing UHIMS was assumed to 
occur at once. This is clearly unrealistic, as the UHIMSs will be phased in over time. However, the purpose of this analysis is simply to rank the UHIMS, rather than to gain an accurate picture of total costs. Therefore, cost over time was not deemed to be necessary for this level of analysis. Further research will be necessary to accurately project unit costs and costs over time.

\section{Cool roofs}

The cost of cool roofs was assigned based on roof type (residential, non-residential), the market share of various roofing materials, and the cost premiums of their cool versions. Only the cost premiums of cool roofing products were used to estimate costs, rather than the full cost of roof replacement. The most common roofing materials, asphalt shingles and built-up membrane roofs, are expected to last from 15 to 25 years (Miller, n.d.). Approximately .067 to $.04 \%$ of roofs are replaced per year, and most asphalt shingle and built-up membrane roofs should be replaced within 25 years. Therefore the natural rate of roof replacement should be sufficiently high to allow for a large number of cool roofs to be installed in any given year.

The non-residential roofing material premiums were assumed to range from $\$ .10$ to $\$ .20$ per square foot, and residential roofing premiums were assumed to be $\$ .64$. It was assumed that $58.8 \%$ of roofs in LA were converted to cool roofs, totaling $18.1 \mathrm{mi}^{2}$. The market share of each roof type was based on data from Dodson (2001). Cost premium 
data was provided by Levinson et al. (2002). Costs for cool roof installation fall primarily on the private sector, although government-owned buildings may also install cool roofs.

Table 11: Costs of cool roofs

\begin{tabular}{|c|c|c|c|c|c|c|c|}
\hline \multirow{2}{*}{ Roof type } & \multirow{2}{*}{$\begin{array}{l}\mathrm{Ft}^{2} \\
\text { converted } \\
\text { to cool } \\
\text { roofs }\end{array}$} & \multirow[b]{2}{*}{ Material } & \multirow{2}{*}{$\begin{array}{r}\text { Share of } \\
\text { respectiv } \\
\text { e roof } \\
\text { market }\end{array}$} & \multicolumn{2}{|c|}{$\begin{array}{l}\text { Cost premium } \\
\text { (\$/sqft) }\end{array}$} & \multicolumn{2}{|c|}{ Cost range } \\
\hline & & & & Low & High & Low & High \\
\hline Residential & $\begin{array}{l}340,611,10 \\
0\end{array}$ & $\begin{array}{l}\text { Asphalt } \\
\text { shingle }\end{array}$ & $100 \%$ & 0.64 & 0.64 & $\begin{array}{l}\$ \\
217,991,104\end{array}$ & $\begin{array}{l}\$ \\
217,991,104\end{array}$ \\
\hline \multirow[t]{5}{*}{$\begin{array}{l}\text { Non- } \\
\text { residential }\end{array}$} & $\begin{array}{l}164,012,57 \\
9\end{array}$ & BUR & $40 \%$ & 0.1 & 0.2 & $\begin{array}{l}\$ \\
6,560,503\end{array}$ & $\begin{array}{l}\$ \\
13,121,006\end{array}$ \\
\hline & & $\begin{array}{l}\text { Single-ply } \\
\text { membrane }\end{array}$ & $18 \%$ & 0 & 0.05 & $\$$ & $\begin{array}{l}\$ \\
1,476,113\end{array}$ \\
\hline & & $\begin{array}{l}\text { Modified } \\
\text { bitumen }\end{array}$ & $10 \%$ & 0 & 0.05 & $\$$ & $\begin{array}{l}\$ \\
820,063\end{array}$ \\
\hline & & Other & $22 \%$ & 0 & 0.05 & $\$$ & $\begin{array}{l}\$ \\
1,804,139\end{array}$ \\
\hline & & & & & Total & $\begin{array}{l}\$ \\
224,551,608\end{array}$ & $\begin{array}{l}\$ \\
235,212,425\end{array}$ \\
\hline
\end{tabular}

Cool pavements

Costs for cool pavements were provided by Nichols Engineers (2012), and Caltrans (2011). Only the cost premiums of cool pavement products were used to estimate costs, rather than the total costs of pavement installation. According to a survey of state's Departments of Transportation, in California flexible pavements, such as asphalt, are designed to last 18 to 20 years, and rigid pavements, such as concrete, are designed to last 20 to 40 years. At this rate, .05 to $.025 \%$ of all roads are replaced each year, and all roads should be replaced within 40 years (Rangaraju, Amirkhanian \& Guven, 2008). 
The costs of road maintenance and construction fall primarily on the pubic sector, however, some concrete and asphalt is installed by private parties on private land, such as driveways and parking lots.

Nichols Engineers found that local contractors in the Chula Vista area charged approximately $\$ .30$ per square foot for the addition of reflective color pigments and seals. Therefore, this figure was used as the cost premium for asphalt, which is used on most surface streets. Caltrans reported that the statewide average cost premium for cool concrete ranges from $\$ .6$ to $\$ 6$ per square foot (Caltrans, 2011). This cost range was used for cool concrete, which is the primary material used on highways.

Table 12: Costs of cool pavement

\begin{tabular}{|c|c|c|c|c|c|}
\hline \multirow{2}{*}{$\begin{array}{l}\text { Roadwa } \\
\text { y type }\end{array}$} & \multirow{2}{*}{ Total area $\left(\mathrm{ft}^{2}\right)$} & \multicolumn{2}{|c|}{ Cost premium / $\mathrm{ft}^{2}$} & \multicolumn{2}{|c|}{ Total cost } \\
\hline & & Low & High & Low & High \\
\hline $\begin{array}{l}\text { Local } \\
\text { roadway }\end{array}$ & $1,028,712,960$ & 0.3 & 0.3 & $\begin{array}{l}\$ \\
308,613,888\end{array}$ & $\begin{array}{l}\$ \\
308,613,888\end{array}$ \\
\hline $\begin{array}{l}\text { Highway } \\
\text { s }\end{array}$ & $50,738,688$ & 0.6 & 6 & $\begin{array}{l}\$ \\
30,443,213\end{array}$ & $\begin{array}{l}\$ \\
304,432,128 \\
\end{array}$ \\
\hline Total & $1,079,451,648$ & & & $\begin{array}{l}\$ \\
339,057,101\end{array}$ & $\begin{array}{l}\$ \\
613,046,016\end{array}$ \\
\hline
\end{tabular}

\section{Tree planting}

Staff from the City of Los Angeles indicated that planting one tree costs approximately $\$ 200$, not including maintenance (personal correspondence, 2014). A cost of $\$ 150$ per tree was also used, in order to introduce a lower range estimate. The costs of tree planting fall primarily on the public sector, even when the trees are installed on private 
property. The City of LA funds programs through several departments and non-profits which heavily subsidize the cost of tree planting on public and private property.

Table 13: Cost of tree planting

\begin{tabular}{|l|l|l|l|l|}
\hline Total number & $\begin{array}{l}\text { New Trees } \\
\text { added }\end{array}$ & $\begin{array}{l}\text { Cost per tree } \\
\text { (\$) }\end{array}$ & \multicolumn{2}{|l|}{ Total cost } \\
\cline { 4 - 5 } & Low & High \\
\hline $34,083,335$ & $6,816,667$ & $180-220$ & $\$ 1,227,000,060$ & $\$ 329,926,682,800$ \\
\hline
\end{tabular}

Solar panels

The total cost of solar panels assumes that over 13 million solar panels were added to rooftops in LA. A survey of the retail prices of major solar manufacturers found that solar panels range from $\$ 200$ to $\$ 315$ each. The total cost was found to be $\$ 1,363,333,401$. The costs of solar panel installation fall primarily on the private sector, however some government buildings may also install solar panels. The financial benefits of solar panels accrue to their owner, and are sufficient to justify solar panel installation, typically paying back the installation cost in less than ten years.

Table 14: Cost of solar panels

\begin{tabular}{|l|l|l|l|l|}
\hline $\begin{array}{l}\text { Area of solar } \\
\text { panels added } \\
\text { (mi. }^{2} \text { ) }\end{array}$ & $\begin{array}{l}\text { Number of new solar } \\
\text { panels added }\end{array}$ & $\begin{array}{l}\text { Cost per solar } \\
\text { panel (\$) }\end{array}$ & \multicolumn{2}{|l|}{ Total cost } \\
\cline { 3 - 4 } & & & Low & High \\
\hline 7.82 & $13,630,555$ & $200-315$ & $\$ 1,363,333,401$ & $\$ 4,293,624,825$ \\
\hline
\end{tabular}




\section{Green roofs}

The average cost of green roofs was assumed to range from $\$ 12$ to $\$ 15$ per square foot. The total cost of green roofs was found to range from $\$ 256,049,429$ to $\$ 320,061,786$. The costs of green roof installation fall primarily on the public sector, although some government buildings may also install green roofs.

Table 15: Cost of green roofs

\begin{tabular}{|l|l|l|l|l|}
\hline $\begin{array}{l}\text { Area of green } \\
\text { roofs added } \\
\left(\mathbf{m i}^{2}\right)\end{array}$ & $\begin{array}{l}\text { Square foot of new } \\
\text { green roofs added }\end{array}$ & $\begin{array}{l}\text { Cost per square } \\
\text { foot } \mathbf{( \$ )}\end{array}$ & \multicolumn{2}{|l|}{ Total cost } \\
\cline { 3 - 5 } & $21,337,452$ & $12-15$ & Low & High \\
\hline .765 & & $\$ 256,049,429$ & $\$ 320,061,786$ \\
\hline
\end{tabular}

\subsubsection{Cost Effectiveness}

The cost effectiveness of each UHIMS was determined by dividing the total cooling provided by each strategy by the total cost. Cool roofs were found to be the most cost effective strategy by far, with $.72{ }^{\circ} \mathrm{C}$ of cooling per $\$ 100,000,000$ invested. The second most cost effective strategy was found to be reflective pavements, at $.15{ }^{\circ} \mathrm{C}$ per $\$ 100,000,000$ invested. Tree planting was found to be somewhat cost effective, at .04 ${ }^{\circ} \mathrm{C}$ per $\$ 100,000,000$ invested. Solar panels were found to be much less cost effective than the other strategies, in terms of cooling. Green roofs were not found to provide measurable cooling, and therefore were the least cost effective strategy. 
Table 16: Cost effectiveness summary

\begin{tabular}{|c|c|c|c|c|c|}
\hline \multirow{2}{*}{$\begin{array}{l}\text { Mitigation } \\
\text { measure }\end{array}$} & \multirow{2}{*}{$\begin{array}{l}\text { Total } \\
\text { cooling (C) }\end{array}$} & \multicolumn{2}{|c|}{ Total cost $(\$ 100 \mathrm{M})$} & \multicolumn{2}{|c|}{ Cooling degree/100M\$ } \\
\hline & & Low & High & Low & High \\
\hline Cool roofs & -0.73 & $\begin{array}{r}\$ \\
2.25\end{array}$ & $\begin{array}{r}\$ \\
2.35\end{array}$ & $(0.33)$ & $(0.31)$ \\
\hline $\begin{array}{l}\text { Tree } \\
\text { planting }\end{array}$ & -0.5 & $\begin{array}{r}\$ \\
10.23 \\
\end{array}$ & $\begin{array}{r}\$ \\
13.63 \\
\end{array}$ & $(0.05)$ & $(0.04)$ \\
\hline $\begin{array}{l}\text { Cool } \\
\text { Pavements }\end{array}$ & -0.46 & $\begin{array}{r}\$ \\
339\end{array}$ & $\begin{array}{r}\$ \\
613\end{array}$ & $(0.14)$ & $(0,08)$ \\
\hline $\begin{array}{l}\text { Solar } \\
\text { panels }\end{array}$ & -0.04 & $\begin{array}{r}\$ \\
27.26\end{array}$ & $\begin{array}{r}\$ \\
42.94\end{array}$ & $(0.001)$ & $(0.0009)$ \\
\hline Green roofs & 0 & $\begin{array}{r}\$ \\
2.56 \\
\end{array}$ & $\begin{array}{r}\$ \\
3.20 \\
\end{array}$ & - & \\
\hline Total & $\begin{array}{l}-1.73 \\
\end{array}$ & 45.68 & 68.25 & -0.51 & -0.42 \\
\hline
\end{tabular}

\subsubsection{Cost Effectiveness Conclusions}

The cost effectiveness analysis indicates that LA should prioritize cool roofs and pavements over other strategies for UHIMS, with cool pavement and tree planting given secondary priority. If fully implemented, these three strategies have the potential to reduce temperatures in LA by $1.42{ }^{\circ} \mathrm{C}$. Solar panels and green roofs should not be prioritized for UHIE mitigation at this time, but may warrant further study. However, solar panels and green roofs may be installed or prioritized for their other benefits, such as energy generation and storm water retention. Cost effectiveness analysis was not performed for "cover increase" as the installation of shade structures would vary so widely in terms of cost. However, this strategy does appear to be effective at UHIE mitigation and therefore warrants further study. 


\subsection{Case Studies}

\subsubsection{Case \#1: Cool Roofs Ordinance and Incentives in New York City}

Enacted: 2011

Implemented by: New York City Local Law 21

\section{Introduction}

New York City is America's largest and densest city, with approximately 8,405,807 residents in just 305 square miles, and is projected to grow by over $1,000,000$ people by 2030. However, New York City's population will be increasingly vulnerable to several climate change impacts, including rising sea levels and increased temperatures. Widespread flooding caused by Hurricane Sandy in 2012 only emphasized the vulnerability of the City's infrastructure. In an effort to address both future development and climate change, PlaNYC was developed in 2007 to address accommodating additional population, repairing aging infrastructure, reducing carbon emissions and adapting to climate change. PlaNYC contains 127 initiatives with achievable milestones, and was updated in 2011 to contain 132 initiatives and more than 400 milestones. Cool roofs were one of the initiatives recommended as part of PlaNYC, which led to the enactment, in 2011, of an ordinance requiring cool roof installation on most low-slope roof alterations or new construction (New York City, 2011). The ordinance was justified as a strategy to mitigate the urban heat island effect, resulting in lower energy use, 
reduced air pollution and greenhouse gas emissions, and improved health and comfort in warm weather (New York City, 2011).

In addition, the City developed a Cool Roofs program within the Mayor's Office of Longterm Planning and Sustainability, with the goal of increasing cool roofs coverage and fostering collaborative projects with academic researchers to improve understanding of the UHIE. The cool roofs program aims to install $1,000,000$ square feet of cool roofs per year.

\section{Requirements of legislation}

The cool roofs ordinance requires "Alterations involving the recovering or replacing of an existing roof covering" to have "a minimum initial solar reflectance of 0.7 in accordance with ASTM C1549 or ASTM E 1918, and a minimum thermal emittance of 0.75 as determined in accordance with ASTM C1371 or ASTM E 408; or a minimum SRI of 78 as determined in accordance with ASTM E 1980" (New York City, 2013).

\section{Implementation progress}

The cool roofs ordinance and programs have been largely successful, dramatically increasing the coverage of cool roofs. According to the City's 2013 progress report, a total of $3,671,032$ square feet of cool roofs has been installed on 416 buildings, with 4,253 volunteers helping with construction. The volunteer roof coating program focuses 
on affordable housing, low-income dwellings, homeless shelters, and housing for seniors and veterans (New York City, 2013).

\section{Text of legislation}

§2. Section 28-101.4.3 of the administrative code of the city of New York is amended by adding a new item 11 to read as follows:

11. Alterations involving the recovering or replacing of an existing roof covering shall comply with section 1504.8 of the New York city building code unless the area to be recovered or replaced is less than 50 percent of the roof area and less than 500 square feet.

§3. Section BC 1504.8 of the New York City building code, as added by local law number 33 for the year 2007 , is amended to read as follows:

1504.8 Reflectance. Roof coverings on roofs or setbacks with slope equal to or less than [three] two units vertical in 12 units horizontal ([25] 17 percent) shall [be white in color or Energy Star rated as highly reflective for at least 75 percent of the area of the roof or setback surface.] have:

1. a minimum initial solar reflectance of 0.7 in accordance with ASTM C1549 or ASTM E 1918, and a minimum thermal emittance of 0.75 as determined in accordance with ASTM C1371 or ASTM E 408; or

2. A minimum SRI of 78 as determined in accordance with ASTM E 1980. 


\subsubsection{Case \#2: Green Infrastructure in Seattle}

Enacted: January, 2007

Implemented by: City of Seattle Ordinance 122311

\section{Introduction}

Seattle's comprehensive landscape design and green infrastructure requirements are referred to as Seattle Green Factor (SGF), and were "modeled after policies developed in Berlin, Germany and Malmo, Sweden" (Jones, 2012). These requirements are the result of a 2007 update to the City's former commercial zoning code, which required a certain amount of open space, based on building square feet. Unfortunately, the former code was found to disincentivize the construction of dense projects within commercial zones by restricting the building footprint and requiring large amounts of open space. The SGF was designed to be more flexible than the prior code and simultaneously to encourage development within the City's core commercial zones and to encourage the installation of green infrastructure. SGF standards were developed with three top priorities: livability, ecosystem services and climate change adaptation.

\section{Requirements of legislation}

The SGF is required "for all new development in neighborhood business districts with more than four dwelling units, more than 4,000 square feet of commercial uses, or more than 20 new parking spaces" (City of Seattle, 2007). The SGF allows developers a menu of strategies with which to satisfy its overall green space requirements, ranging from bioretention facilities to tree planting to green roofs. SGF accomplishes this by 
using a score sheet, which keeps track of the number of plantings or total square footage of each strategy. Each strategy is given a weight, for example: green roofs with over 4" of growing medium are weighted at .7, while ground level plantings are weighted at .1. Tree canopy preservation is incentivized through a higher weight for existing trees (.8) than for new plantings (.3 to .4). Landscaping in the public right-of-way adjacent to the project parcel is considered equivalent to landscaping on the project parcel, creating a strong incentive for streetscape improvements. Additional bonuses are provided for rainwater harvesting and/or low water use plantings. The score sheet must reflect a score or .3 in order for the requirement to be met, which translates into roughly $30 \%$ of the area of the parcel being vegetated.

\section{Implementation progress}

In 2010, the Seattle Department of Planning and Development received an honor award from the American Society of Landscape Architects for the SGF program. According to the ASLA, as of 2010, "approximately 200 projects have been permitted through the SGF. Many are stalled due to the current recession, but about 30 are built or close to completion. Because SGF significantly raises the bar for landscaping in affected zones, landscape design now starts in the initial states of site planning, allowing more collaboration between design professionals; the resulting landscapes are more attractive and better integrated into site programs and amenity areas" (2010). Since 2010, Seattle economy has rebounded, with strong development in the downtown commercial areas. In December 2014, downtown Seattle saw nearly 100 active 
construction projects, the highest count since tracking began in 2005 (Downtown Seattle Association, 2015). Most, if not all, of this new development will be subject to the SGF requirements.

\section{Text of legislation}

23.45.524 - Landscaping standards

A. Landscaping requirements

1. Standards. All landscaping provided to meet requirements under this Section 23.45.524 shall meet standards promulgated by the Director to provide for the long-term health, viability, and coverage of plantings. These standards may include, but are not limited to, the type and size of plants, number of plants, spacing of plants, depth and quality of soil, use of drought-tolerant plants, and access to light and air for plants.

2. Green Factor requirement

a. Landscaping that achieves a Green Factor score of 0.6 or greater, determined as set forth in Section 23.86.019, is required for any lot within a LR zone if development is proposed that has more than one dwelling unit, or a congregate residence. Vegetated walls may not count towards more than 25 percent of a lot's Green Factor score.

b. Landscaping that achieves a Green Factor score of 0.5 or greater, determined as set forth in Section 23.86.019, is required for any lot within a MR or HR zone if 
development is proposed that has more than one dwelling unit or a congregate residence. 


\subsubsection{Case \#3: Mandatory Solar Panel Installation in Lancaster, CA.}

Enacted: January 1, 2014.

Implemented by: Chapter 17.08 of the Lancaster Municipal Code

\section{Introduction}

In 2013 the City of Lancaster became the first U.S. city to require the installation of solar photovoltaic (PV) panels on new homes. Lancaster is a city of about 160,000 people, located in the high desert to the north-east of the City of Los Angeles. Despite enjoying more than 300 days of sunshine per year, Lancaster is not a politically liberal city, making it a somewhat unlikely location for progressive clean energy laws. The Mayor, R. Rex Parris, a Republican, described the legislation as part of a plan to make Lancaster "the solar capital of the universe" (Trabish, March 2013). The Mayor is aggressively pro-business, and sees the ordinance as an economic development tool. He told the New York Times that entrepreneurs should know "that if they come and have an idea to create energy without a carbon footprint" the local government will "move mountains for them" (Barringer, April 8, 2013). The Mayor has also stated that "the salvation of this planet, if it is not already too late, will be from the bottom up, and there is no reason Lancaster can't be the example for the world" (Trabish, March, 2013).

\section{Requirements of legislation}

The Lancaster City Council unanimously approved changes to the City's zoning and municipal code which created specific minimum size requirements for PV systems on new homes, based on the project's zoning. According to the City website, the 
legislation was designed to implement "the goals and objectives of the latest General Plan, adopted in 2009", and also included other changes to the zoning ordinance, such as new design guidelines, infill development incentives, and the allowance of accessory dwelling units and live-work units (City of Lancaster, 2013). Newly constructed single family homes in "infill" zones must include a $1 \mathrm{~kW}$ solar system as minimum, while new single family homes in the "rural residential" zones must install a $1.5 \mathrm{~kW}$ system. Apartment complexes and planned unit developments can aggregate their panel installations, but must also achieve a minimum size per unit of new development. In addition, builders "may choose to meet the solar energy generation requirement off-site by providing evidence of purchasing solar energy credits from another solar-generating development located within the City" (City of Lancaster, 2013).

\section{Implementation progress}

Environment California, an environmental research and lobbying group, estimated that the City tripled the number of residential installations after announcing the requirement. As shown in table 4.2-1 and 4.2-2, Lancaster ranks fourth in total installed solar capacity in California at over 30 megawatts, and $11^{\text {th }}$ in California in the number of solar applications, at 1,356 (California Solar Statistics, February, 2015). However, Lancaster ranks first in solar capacity per capita, at about 195 Watts, and $7^{\text {th }}$ in applications per capita (California Solar Statistics, February, 2015). By all measures, Lancaster's solar requirements, along with other efforts to promote solar installation, have made Lancaster one of the top solar cities in California. 
Table 17: Solar capacity by city in California

\begin{tabular}{|c|c|c|c|}
\hline City & $\begin{array}{l}\text { Solar Capacity } \\
\text { (MW) }\end{array}$ & Population & Capacity per capita (W) \\
\hline San Diego & 63.5 & $1,345,895$ & 47.18 \\
\hline San Jose & 57.9 & $1,000,536$ & 57.87 \\
\hline Bakersfield & 33.2 & 363,630 & 91.30 \\
\hline Lancaster & 31.1 & 159,523 & 194.96 \\
\hline
\end{tabular}

Table 18: Solar application by city in California

\begin{tabular}{|l|c|c|c|}
\hline City & \# of applications & Population & $\begin{array}{l}\text { Applications per } \\
\text { capita }\end{array}$ \\
\hline Murrieta & 1,755 & 103,466 & 0.017 \\
\hline Clovis & 1,563 & 101,314 & 0.015 \\
\hline Temecula & 1,428 & 105,208 & 0.014 \\
\hline Corona & 1,931 & 158,391 & 0.012 \\
\hline Bakersfield & 3,137 & 363,630 & 0.009 \\
\hline Lancaster & 1,356 & 159,523 & 0.009 \\
\hline Santa Rosa & 1,382 & 171,990 & 0.008 \\
\hline Fresno & 2,573 & 509,924 & 0.005 \\
\hline San Jose & 4,270 & $1,000,536$ & 0.004 \\
\hline San Diego & 5,496 & $1,345,895$ & 0.004 \\
\hline San Francisco & 2,936 & 837,442 & 0.004 \\
\hline
\end{tabular}




\section{Text of legislation}

17.08.305 - Implementation of solar energy systems.

A. Purpose and intent. It is the purpose and intent of this section to provide standards and procedures for builders of new homes to install solar energy systems in an effort to achieve greater usage of alternative energy.

B. Applicability. These specific standards are applicable for all new single-family homes with a building permit issuance date on or after January 1, 2014 .

C. Provision of solar energy systems.

1. A builder shall provide solar energy systems for new homes in accordance with the energy generation requirements as listed in section 17.08.060.

2. Installation of solar energy systems is not required for all homes within a production subdivision; however, the builder shall meet the aggregate energy generation requirement within the subdivision (as calculated by the per-unit energy generation requirement multiplied by the number of homes in the subdivision). For example, an R7000 subdivision with ten (10) homes that is required to provide $1.0 \mathrm{~kW}$ per unit would have an aggregate energy generation requirement of $10 \mathrm{~kW}$ for the subdivision. The 10kW energy generation requirement can be met with two homes having solar energy systems generating $5 \mathrm{~kW}$ each, or with four homes having systems generating $2.5 \mathrm{~kW}$ each.

3. Homebuilders shall demonstrate through building plan check their intention to meet the solar energy generation requirement. 
4. Homebuilders shall build solar energy systems on model homes, reflective of the products that will be offered to homebuyers.

5. If a tract is built in phases, the solar energy generation requirement shall be fulfilled for each phase.

6. Solar energy systems shall meet the development standards and guidelines as described in this section.

7. Solar energy systems for multi-family developments may be provided on rooftops, or on solar support/shade structures.

D. Off-site fulfillment of solar energy generation. A homebuilder may choose to meet the solar energy generation requirement off-site by providing evidence of purchasing solar energy credits from another solar-generating development located within the city. 


\subsubsection{Case \#4: District of Columbia Stormwater Fee and Green Roof Incentive Program}

Enacted: 2010

Implemented by: Title 21 of the District of Columbia Municipal Regulations, Chapter 5 , "Water Quality and Pollution," Section 556.

\section{Introduction}

The District of Columbia's green roof incentives result from the combination of a unique storm water fee system, and direct monetary incentives for green roof construction. In 2008, the District established a stormwater fee system to pay for infrastructure required to comply with its MS4 Permit Enhancement Agreement with the U.S. EPA Region III. This fee is assessed monthly on all properties within the district, and is based on the amount of impervious surface area on the property. Impervious surfaces shed the rainwater that falls on them into surrounding stormwater infrastructure, requiring larger facilities and treatment systems. While most cities pay for stormwater infrastructure though fees added to water bills, the District has created a more equitable fee system, in which those properties that contribute more stormwater to the system pay more, rather than those properties that use more tap water (which is not directly related to stormwater). Initially, the District's stormwater fee was equal for all residential properties, regardless of size. However, in 2010, the fee schedule was changed to a tiered system, based on impervious surface area. This fee schedule creates a monetary incentive for residential and commercial properties to reduce their impervious surface 
area, thereby reducing their monthly stormwater bill. Green roofs are considered pervious surfaces, and have been found to be highly effective at retaining stormwater, especially in urban areas where space is limited for ground-level retention. However, the capital cost of green roof installation can be high, ranging from $\$ 12$ per square foot to well over $\$ 60$. Therefore, in 2007 , the District established a green roof incentive program, to help defer the capital cost of green roof construction. This program initially provided a base rebate of $\$ 3$ per square foot, which has since increased to $\$ 10$ per square foot, and up to $\$ 15$ per square foot in targeted sub-watersheds. In addition, the Distract has established a stormwater credit trading mechanism, in which property owners who voluntarily install green infrastructure to manage more than their required amount of stormwater may sell "Stormwater Retention Credits" to property owners within the same watershed who are not able to retain sufficient stormwater on their own properties. This trading mechanism leads to more cost-effective retention, by incentivizing those who can cheaply retain stormwater to retain more.

\section{Requirements of legislation}

Each 1,000 square feet of impervious surface area on a property is taxed at a rate of (\$2.67) per month. Landlords cannot pass a stormwater charge to a tenant that is more than this stormwater charge. 


\section{Text of legislation}

\section{STORMWATER FEES}

556.1 Effective May 1, 2009, the stormwater fee collected from each District of Columbia retail water and sewer customer shall be based upon the Equivalent Residential Unit (ERU). An ERU is defined as 1,000 square feet of impervious area of real property.

556.2 A residential customer means a single-family dwelling used for domestic purposes, a condominium or apartment unit where each unit is served by a separate service line and is individually metered and the unit is used for domestic purposes, or a multifamily structure of less than four apartment units where all the units are served by a single service line that is master metered. Residential customers shall be assessed ERUs for the square feet of impervious surface on the property, as follows:

(a) 0.6 ERUs for 100 to 600 square feet of impervious surface;

(b) 1.0 ERU for 700 to 2,000 square feet of impervious surface;

(c) 2.4 ERUs for 2,100 to 3,000 square feet of impervious surface;

(d) 3.8 ERUs for 3,100 to 7,000 square feet of impervious surface;

(e) 8.6 ERUs for 7,100 to 11,000 square feet of impervious surface; and

(f) 13.5 ERUs for 11,100 square feet or more of impervious surface.

556.3 All non-residential customers shall be assessed ERU(s) based upon the total amount of impervious area on each lot. This total amount of impervious area shall be 
converted into $\mathrm{ERU}(\mathrm{s})$, reduced to the nearest 100 square feet. Non-residential customers shall include all customers not within the residential class.

556.4 Impervious-only properties are properties that have not, prior to May 1, 2009, had metered water/sewer service and require the creation of new customer accounts for billing of stormwater fees. The DC Water and Sewer Authority, pursuant to the Water and Sewer Authority Establishment and Department of Public Works Reorganization Act of 1996, effective April 18, 1996 (D.C. Law 11-111, §§ 203(3), (11) and 216; D.C. Code $\S \S 34-2202.03(3),(11))$, shall establish accounts for and bill these impervious-only properties for stormwater fees pursuant to its regulations in 21 DCMR Chapter 41. 556.5 The charge for one Equivalent Residential Unit (ERU) shall be two dollars and sixty-seven cents (\$2.67) per month. This charge shall become effective November 1 , 2010.

556.6 A landlord shall not pass a stormwater charge to a tenant that is more than the stormwater charge prescribed by the Director.

\section{Implementation progress}

The combination of a capital cost rebate up front, and a monthly savings on stormwater bills has proved to be a powerful incentive for property owners to install green roofs. According to national surveys by the green roof industry, the District went from a very small number of green roofs in 2005 , to the number one city for new green roof installation in 2010 , and the number one city for total installed green roofs by 2012 , 
surpassing even the city of Chicago, which is well known for its green roofs. Today, the District is estimated to have over 2,000,000 square feet of installed green roofs (GRHC, 2014). 


\subsubsection{Case Study Conclusions}

The case studies of Seattle, WA, New York City, NY, Washington D.C. and Lancaster, CA each provide an example of successful implementation of strategies to reduce the UHIE. Several conclusions can be drawn from these case studies: UHIE mitigation was often a motivating factor (but usually a co-benefit), the policies did not experience political backlash, and the policies were largely successful.

Three of the four case study policies were implemented with IHIE reduction as a stated goal, but none were implemented for UHIE reduction alone. In case \#3, economic development was cited as the major goal of solar panel installation, with GHG mitigation as a secondary goal. In the other cases, UHIE mitigation was seen as one of several equally important co-benefits. In case \#4, the co-benefit was storm water capture, in case \#1 the co-benefit was energy savings, and in case \#2 the co-benefits were aesthetics and storm water capture. In terms of policy formation, the co-benefits of UHIE reduction are clearly as important as, or more important than, UHIE reduction alone.

None of the case study policies appeared to experience political backlash. This may be due to the emphasis on direct financial incentives to property owners or developers inherent in each policy. For example, in case study \#4, generous tax rebates and ongoing monthly utility bill savings provide a strong financial incentive to install green roofs. In case study \#3, electricity bill savings and new solar funding models, which require zero down payments, make solar panels a worthwhile investment. In case study 
\#2, the new Seattle Green Factor requirements are more flexible (and likely less expensive) than previous landscaping requirements, making them more amenable to the development community. In case study \#1, the City of New York provided grants and tax incentives for early adopters of cool roof coatings, and the additional costs of the coatings are small in the context of a re-roofing project, as shown in section 4.1.3.

Even though not all of the case studies aimed specifically to decrease the UHIE, they all appear to have been highly successful at accomplishing the goals of their legislation. For example, in case study \#3, Lancaster now has the highest per-capita solar installations, and among the highest number of applications for new installations, in California (the state with the largest installed solar capacity). In case study \#2, Downtown Seattle has experienced an economic boom, with the largest number of new construction projects since that data collection began in 2005. The SGF was also found to produce more attractive and better integrated landscapes. In case study \#1, New York City has installed over $3,671,032$ square feet of cool roofs. In case study \#4, Washington D.C. has surpassed Chicago to become the US leader for installed green roofs and green roof square footage per capita. These case studies indicate that urban heat island mitigation legislation can clearly be successful if financial incentives are provided and co-benefits of HIMS are emphasized along with UHIE mitigation. 


\subsection{Interview Findings}

\section{Question 1: What progress has been made toward adapting to climate change in}

\section{LA?}

Interviewee 1: The City invested in a partnership with UCLA, to determine what the climate will be like in 40 or 50 years. They funded a professor to produce data on what the likely temperatures and climate for LA will be in the time period between 2040 and 2060. They chose that time period so they would have time to implement adaptation measures. This professor is also looking at water supply, rain, wind temperature, and five or six different parameters. Based upon that data, they have started moving forward (with policies). Los Angeles had recently passed an ordinance requiring cool roofs (on low-slope roofs), and the science provided by the UCLA study was essential to passing that legislation. The City has looked into reflective pavements, but that they haven't found a good material that would work well for them yet, as they make their own asphalt and are very proud of that fact. In terms of tree planting, early efforts were intended to reduce the urban heat island effect, so many trees were planted in the downtown area. The Million Trees Initiative led to the planting of about 300,000 trees.

Interviewee 2: There have been for years programs largely funded by local utilities, from the DPW to SoCal Edison to plant trees for energy savings through shading, though those haven't been called 'climate adaptation' strategies. These measures reduce energy use, because if the tree is planted correctly is reduces air conditioner uses and 
therefore reduces energy use. This cools the home, mitigates the urban heat island effect, and reduces greenhouse gas emissions. This is simultaneously climate mitigation and adaptation in a sense, however, it is not called that. In the interviewee's experience climate adaptation has been a motivating factor for tree planting programs in the past.

Another theme popularized by Tree People is heat related mortality. Professor Nigel Tapper of Monash University in Melbourne, Australia, is a leading researcher in this field. Australia underwent a very devastating drought that was coupled with intense heat waves; they found that cities that experience increased heat events, hotter temperatures and lengthier periods of sustained heat, are experiencing increased mortality. After three days of sustained heat without nighttime cooling, elderly people are at high risk. This increased mortality is happening much more frequently in neighborhoods that have less tree canopy. This is a theme that hasn't been explored in Southern California much. Interviewee 2 hopes that in the coming months and years, we are going to be hearing more and more about tree planting to prevent heat-related mortality.

Interviewee 3: The City is still formulating what it is doing for climate change. Generally, climate adaptation is spoken about in the language of sustainability (the efficiency and reduction of consumption and production of waste). A multi-pronged approach is needed, because there are different ways to affect the built environment. Tree planting is a major one, depending on the community. Cool roofs are great depending on the size of the structure. Reflective pavements are interesting, and are addressed in the 
landscaping ordinance, especially with walls and surface materials. Solar panels are supporting all this, but must be put in aesthetically, if possible. One of the elements of urban design is sustainability. Climate adaptation can be dealt with through reduced demands, for power, heat, cold, and water, and by making sure buildings are self sufficient in terms of water and energy. The green building ordinance and the building codes have pushed structures towards sustainability. Buildings are integrating alternative strategies for cooling, as opposed to just air conditioning, but this is more common with larger buildings. Smaller buildings are not doing that yet. The City put sustainability into design guidelines for people to think about, not in terms of adaptation, but in terms of efficiency, to cool or to heat buildings.

One example is the small lot design guidelines. Not many dwelling units are produced under that category each year, but LA just produced guidelines for that category. These guidelines include suggestions on sustainability and landscaping. It is also necessary to push the building codes, the storm water capture requirements, the shade tree requirements, to think about energy efficiency.

Summary: Interviewees gave several examples of progress that LA has made toward adapting to climate change, including detailed studies about LA's future climate, tree planting programs that have led to the planting of 300,000 trees, and the incorporation of sustainability concepts into building codes and the small lot design guidelines. 


\section{Question 2: What UHIE measures should be prioritized?}

Interviewee 3: LA extends from San Pedro up to Sylmar, from inland to coastal, with hillsides, canyons and diverse geographies. It is a very geographically diverse area. Some strategies work better in some areas than others. In the San Fernando Valley, cool roofs might work better, while on the coast, maybe street trees, or reflective pavement or solar panels would work better. Having a greater range of options would be more efficient because there are a variety of contexts within which these will be implemented. They all could work, depending on the topology, whether the site is a built-out or natural area, and other factors.

Interviewee 4: Tree planting and cool roofs. Interviewee 4's focus is on downtown so that is what comes to mind. Downtown's tree canopy is lacking, in large part because the legacy of downtown is industrial. The City structures in place don't bode well for getting trees planted where they need to be. The rest of the City is doing a little better with trees so solar panels or the building orientation are more important for the rest of the city.

Summary: Interviewee's seemed to think that different UHIE measures should be prioritized in different areas, depending on local conditions. Interviewee 4 thought that tree planting and cool roofs should be prioritized in downtown LA. 


\section{Question 3: Have any UHIE measures been difficult to implement?}

Interviewee 1: Not at all, because the data shows that increased heat is coming. The City had been looking at cool roofs for some time, and put one on the Public Library in Downtown LA. The library was thrilled to get it because the roof was leaking, in addition to not being very thermally protected. In order to put the cool roof on, they had to stop traffic and close down a couple of lanes of traffic. During rush hour this part of downtown can be quite a mess, so they thought it might cause problems. However, they put up informational posters, put stories in the paper and had grad students out there telling people what was going on. As a result, it went a lot better than they thought it would.

Interviewee 2 couldn't think of any opposition to tree planting or other UHIE measures. On the contrary, sometimes there is opposition when a city or developer attempts to cut down trees. When Interviewee 2 was training as a citizen forester they did a lot of walking around asking if people wanted trees. They went to a commercial area, and some businesses want trees and others said 'no' we don't want trees because it will block our signs.

Interviewee 3: The one UHIE strategy that is more controversial, because it is more complicated, is building geometry and street width. That intersects with private property and the way we do subdivisions, orient the buildings to the street, and orient the buildings on the site, making it more complicated. 
Summary: Interviewees thought that UHIE measures had not been difficult to implement in LA, due to generally positive reception in the community. The exceptions were building geometry (structural shading), which could be controversial, and some business owners who don't like street trees because they could block views of their stores and signs.

\section{Question 4: What level of community or political support do UHIE measure enjoy}

\section{in LA right now?}

Interviewee 2: It depends on what community. Interviewee 2's organization is a volunteer organization that works with about 12,000 volunteers per year to plant trees and care for trees. They found that people can be very interested in being a steward of the environment, such as by planting trees. They are not the only urban forestry program in the area, but their approach is unique in that they use the 'citizen forester model'. They don't actually go out and do any tree planting. They work with individuals in the community who want to be leaders, and train them to do a variety of different tasks from volunteer coordinating to picking the right tree to pulling permits to developing a maintenance plan for their planting. They do the training and give volunteers the tools and resources, but then it's their responsibility to do the planting. Therefore, they know that there is a lot of community interest. There is a contingent in LA that is very interested in tree planting. However, there are areas of the City and county that have much lower tree canopy than the wealthier parts of town. In some 
cases there are community leaders who are really interested in increasing the tree canopy in their neighborhood and do a lot of work for that. In other cases it is hard to find leaders who can prioritize tree planting in an area where there's a lot of other social and economic pressures for things that have nothing to do with the environment.

Interviewee 4: Everyone understands climate change here, especially in City government, and there's an appetite for it. However, the political will is missing. For things to happen here there needs to be a political champion in City Hall. The City departments do their own thing and are trying to incorporate adaptation as they can, but a coordinated approach is lacking. Planning can do its part, but without bureau of engineering or street services on board, they can only take it so far. Planning can only address the public realm, but the private realm needs to be incorporated as well.

Summary: Overall community support for UHIE measures is high in LA, but can vary by neighborhood. Some neighborhoods may have more pressing social issues to deal with. The political will on the part of City government may be lacking.

\section{Question 5: What are the main barriers to implementing UHIE measures in LA?}

Interviewee 2: The barriers are two-fold. One is the perception that because of the drought we shouldn't plant trees. However, the average lawn in LA requires tens of thousands of gallons of water per year, and replacing that number of gallons per year could support several dozen trees. There's a lot of water used to support vegetation that 
doesn't belong in a Mediterranean environment. Another barrier is the maintenance. There's a real concern on the part of the City, school districts and the Los Angeles Department of Parks and Recreation that trees take maintenance, especially for the first five years. Maintenance requires money to pay for non-volunteer staff time.

Interviewee 4: The Fire and Building and Safety departments are a big barrier to green roofs. LA has a very siloed City government, in which each department responds to its own needs, and does not coordinate unless directed to. Fire requires that every building over a certain size have a helipad maintained free and clear. Building and Safety is uncomfortable with green roofs because they are outside their comfort zone. The Planning Department is more excited about green roofs. The Planning Department can write the policy, but if there's no one to take it forward, it is not going to go anywhere. Solar panels don't appear to have a barrier. For reflective pavements, the way the city operates is the biggest barrier. If they haven't tested it and put it on the approved list of how they do things, they aren't going to do it. With street trees, LA has ridiculous requirements for separation between utilities, ingress and egress (curb cuts), and where street trees can be planted. Planning will come up with great things such as wanting a continuous canopy, but once all these other departmental requirements are included, trees can only be planted every fifty feet, at best. There also isn't a good organization in place to trim trees and maintain them. Therefore the Tree Service Department doesn't want new trees planted because of the ongoing maintenance costs, which is a horrible structure. Maintenance is important, but we need a better system or a coordinating 
agency. Planning has attempted to consolidate that under our control, but has been met with resistance from all of those permitting agencies, which have their own vested interest in maintaining their structure. There are also union issues, for example, if someone is in DOT and then, all of a sudden, in planning, promotional opportunities might seem limited.

Again it comes down to political will. LA has a weak mayor system; therefore all fifteen council offices need to be onboard too. Our communities, especially downtown, are really invested in climate change and sustainability. At community meetings sustainability is usually one of the first things heard from the community. I don't know how the valley is, or other parts of the City that might actually be more impacted by climate change.

Summary: Tree planting has several barriers to overcome, including the perception that LA is in a drought, and the need for maintenance. The siloed nature of City government and the lack of a champion in City Hall has been a barrier to HIMS.

\section{Question 6: Do you have any suggestions for regulatory incentives?}

Interviewee 2: The Los Angeles Department of Building and Safety gives a short menu of options for complying with a particular standard, such as the low-impact development ordinance, which is aimed at reducing the amount of runoff that redeveloped or newly developed properties can produce. Increasing vegetation and tree cover is one of the 
ways that a developer or homeowner can come into compliance with that. In terms of financial incentives, free trees is probably the most direct way to go about increasing the tree canopy. There are other parts of the country that have looked at the link between water and trees, and municipalities that have a storm water tax based on how much of the property is impervious. Reducing the tax burden would be quite an incentive.

Interviewee 3: Economic incentives work, depending on what kind. Incentives should be the easiest thing to do, clear, less regulated, and efficient. Decreased regulation should come with the tradeoff of doing the right thing. Developers like to have things processed quicker. For example, if you do LEED you get bumped up to the front of the line, saving time for developers.

Summary: Possible regulatory incentives for UHIE measures could include compliance with low-impact development standards, a reduced tax burden, decreased regulation, or faster permitting.

\section{Question 7: As far as existing incentives, are there any that you know of?}

Interviewee 2: There are incentives through utilities. The one that DPW offered was called Trees for a Green LA. That one is up in the air; it used to be DPW then went over to the Public Works Department. Depending on location there are generally free trees provided for residential and business users. Cal Edison also provides that for areas outside the City of LA. 
Summary: Existing incentives include those offered by DPW for tree planting.

\section{Question 8: How might mandatory measures be perceived?}

Interviewee 2: Any time something is mandatory, there will be a contingent that is not supportive of it. Commercial tenants or owners may have concerns. A commercial parking lot might be concerned about lost parking spaces or maintenance. However, there are a number of different avenues to pursue this. The Department of Building and Safety is working on an ordinance that will require all new development to provide $25 \%$ shade on their properties. It doesn't have to be necessarily with trees; it could also be shade structures. This requirement is coupled with one relating to impervious surfaces. The Department is looking for a $25 \%$ reduction in impervious surfaces, or ensuring $25 \%$ of the property is shaded. People follow building and safety codes because they're enforced. There are ways of doing adaptation that could be easily passed and implemented.

Summary: Business owners and residential building owners may oppose mandatory measures, but more flexible ordinances could be better received.

\section{Question 9: How many trees are being planted in LA?}

Interview 2: Interviewee 2's organization tracks how many trees they plant, and Million Trees LA keeps track of how many they plant, but a lot of tree planting happens on 
private property and outside of these programs. The Urban Forestry Division of the City of LA keeps a general inventory, and it's at about 700,000 . They keep track of these numbers but they also want to know how many of these trees are dying.

LA is looking at doing tree cover canopy analysis, and setting up goals to look at tree cover canopy. A million trees is great, but goals should be based on tree canopy percentage instead of pure numbers. The US Forest Service has, within their Southwest Division, a program called Urban Ecosystems and Social Dynamics. They have valuable guides for different cities, and conducted the Million Trees LA tree canopy cover analysis. It does more on the research side of things than the policy and regulatory side.

Summary: About 700,000 trees have been planted through various programs since 2006.

\section{Question 10: Has there been any investigation in terms of buildings design and street width for heat island reduction?}

Interviewee 3: The King of Spain set up downtown LA, not in a true N-S-E-W grid, but at a 35 degree angle. This strategy was brought from a Mediterranean climate, which gives more efficiency in cooling, in hotter climates. When LA became the U.S., in the 1,800s, we went to the Franklin method, a true N-S-E-W. However, in a Mediterranean climate there is more heat gain with a true N-S-E-W, so it's less efficient in general. For example, a generic box, in relation to the street edge, has more heat gain, especially on 
the southern side. If there is a 35 degree angle, there is less heat gain. Building orientation is very difficult to change, because of the building's relationship to the street.

Summary: Interviewee 3 was not aware of specific studies of building design and heat island reduction in LA, but the City's original street grid was laid out to minimize heat gain.

\section{Question 11: How could this study be more relevant to you?}

Interviewee 1: It would be useful to the Department and to the City as a whole. Usually there is one particular program but not an overall study of what it would mean in conjunction with others. During the development of the cool roofs ordinance, some studies were looked at, but they weren't overall city-wide studies. Reflective pavements were studied, but not on a city-wide basis. That would be very hard to measure, because it is done by different development types, and sometimes it's done by public works projects. It would be very interesting to get the planning department and the City thinking about where that could lead. Approaching it from different ways, and analyzing what it would mean if you put this all together, would be useful.

Interviewee 3: Interpret what the study and the results mean for planners and designers. That would be very helpful for moving forward from the study to implementation. Outline the next steps, suggestions and directions. Demonstrate that it's a good idea. Present examples such as, New York is doing it this way, and here are the key directions and 
steps, or San Antonio is doing this and here are their key steps. Show that LA should follow these strategies and these steps, or study this further. That would give the council members or the mayor's office an idea of the value of this and gives them the first two or three steps.

Summary: The study would be useful for interviewees if it took into account all UHIE measures in an integrated manner, and was interpreted specifically for designers and planners, with examples and directions.

\section{Question 12: Do you have any suggestions for adaptation goals?}

Interviewee 3: Look at what it might mean depending on who would implement it. Look at what it would mean for peak energy consumption for the peak days. Look at system efficiencies and what it might mean for an aging population during peak heat times. It could also save lives, so look for these dramatic points, because that would be a motivation for implementing this. Adaptation isn't just a good idea, it also has an economic and energy efficiency and health and safety value. Those would be the key points they would make and have goals based on that. Show what it would do in terms of energy consumption if you kept the temperatures the same, if you be able to house more people but still have the same energy consumption.

Summary: Goals for climate adaptation could be geared towards who implements them, and what they mean for peak energy consumption or mortality. 


\section{Question 13: Does your department have any environmental goals?}

Interviewee 3: Only what the City Council sets. The Department is looking at various efficiencies, such as changing over the fleet to hybrid vehicles or electric instead of diesel. The department is studying what percentage of waste is being recycling. This has happened a little bit on the city level but without any specific plan yet. The mayor has a new sustainability deputy and he's probably formulating those goals for the mayor. Follow him and follow the mayor's office to see where they're going.

Summary: The LA City Council sets environmental goals for the City departments.

\section{Question 14: Any comments on the future heat and adaptation in LA?}

Interviewee 4: The Planning Department is very aware of climate adaptation, with the approach of addressing the transportation-land use connection, both in adaptation and the reduction of emissions. Placing people and transit densely around transit nodes and building out transit to our nodes. The Planning Department is actively, through community planning, rezoning the city with that in mind, with the underpinning of climate change. The second way the Planning Department addresses adaptation is encouraging adaptive re-use. LA has a huge stock of historic structures, so the Planning Department has tried to make it as easy as possible to do adaptive re-use with seismic upgrades. The Department won't let people re-inhabit buildings that aren't seismically sound. Parking requirements may be waived, but not seismic requirements. The 
Department wants to avoid creating a system where all these people into historic buildings and then they collapse in an earthquake.

Summary: The planning department is actively addressing climate adaptation and mitigation through the land use and transportation connection, and through adaptive reuse of existing buildings.

\subsection{Interview Conclusions}

LA has made significant progress toward adapting to climate change, including detailed studies about LA's future climate, tree planting programs that have led to the planting of 700,000 trees, and the incorporation of sustainability concepts into building codes and the small lot design guidelines.

Different HIMS should be prioritized in different areas, depending on local conditions. For example, tree planting and cool roofs should be prioritized in downtown LA.

Interviewees thought that HIMS had not been difficult to implement in LA, due to generally positive reception in the community. The exceptions were building geometry (structural shading), which could be controversial, and some business owners who don't like street trees because they could block views of their stores and signs. Overall community support for HIMS is high in LA, but can vary by neighborhood. Some 
neighborhoods may have more pressing social issues to deal with. The political will on the part of City government may be lacking.

Specific HIMS, such as tree planting and green roofs have several barriers to overcome, including the perception that LA is in a drought, and the need for maintenance. The siloed nature of City government has been a barrier to HIMS, as well as the lack of a champion in City Hall.

Existing incentives include those offered by DPW for tree planting, which have led to about 700,000 trees being planted through various programs. In order to increase the adoption of HIMS, possible regulatory incentives for UHIE measures could include compliance with low-impact development standards, a reduced tax burden, decreased regulation, or faster permitting. Mandatory measures may be opposed by business owners, but more flexible ordinances could be better received.

Interviewees thought this study would be useful if it took into account all UHIE measures, and was interpreted specifically for designers and planners, with next steps and directions. Goals for climate adaptation could be geared towards who implements them, and what they mean for peak energy consumption or mortality. 


\section{CHAPTER 5: CONCLUSIONS AND RECOMMENDATIONS}

In the introduction and literature review, the impacts of climate change in LA are outlined in detail. Average temperatures in LA are projected to increase by $.6^{\circ} \mathrm{F}$ to $6.5^{\circ} \mathrm{F}$ as early as 2050 (Hall et al., 2012, p. 29). In addition, the number of extreme-heat days are projected to increase from an average of 5.6 days per year to between 10 and 48 days per year by 2050 (Hall et al., 2012, p. 29). This increase in both average and high temperature will have extreme consequences for public health and the environment, through the increases in photochemical smog, electricity use for cooling, and heat related illness and mortality. Temperatures in LA are already elevated due to the urban heat island effect, in which urban surfaces absorb and radiate more heat than surrounding natural areas. The UHIE is thought to increase LA's cooling-degree days by 92 percent (Haider, 1997). Los Angeles has made significant progress towards reducing its UHIE, including detailed studies about LA's future climate, tree planting programs that have led to the planting of 700,000 trees, and the incorporation of sustainability concepts into building codes and the small lot design guidelines. However, further UHIE mitigation measures will be necessary in order to reduce the impacts of future climate change.

Large scale interventions in the built environment have been shown to reduce the UHIE, and thereby reduce the impacts of global warming. In order to affect the city as a whole, these interventions must be implemented at the urban design scale, meaning that they require the modification of vast areas of the urban landscape. These UHIE mitigation 
measures include green infrastructure, such as tree planting and green roofs, reflective roofing materials, reflective pavements and solar panels. These strategies are not mutually exclusive, but they vary in terms of their cooling potential, cost, and political feasibility. Previous research has focused on the cooling effectiveness of UHIE mitigation measures, using computer-based climate models to predict how changes in the built environment can affect ambient temperatures. However, this research has largely ignored the cost of installing UHIE mitigation measures on a large scale, and the political feasibility of passing UHIE mitigation policies. This study addresses this research gap by assessing UHIE mitigation measures more holistically, incorporating both cost data and a qualitative assessment of political support, in addition to cooling effectiveness data from previous researchers. The primary objective of this study was to answer the following three questions related to climate change adaption in LA:

1. What urban design policies are most cost-effective for reducing temperatures in $L A ?$

2. How politically and socially acceptable are climate adaptation strategies?

3. How can climate adaptation policies best be implemented?

Question 1: What urban design policies are most cost-effective for reducing temperatures in LA?

Findings from the cost effectiveness analysis indicates that LA should prioritize cool roofs and pavements over other strategies for UHIE mitigation, with cool pavement and 
tree planting given secondary priority. If fully implemented, these three strategies have the potential to reduce temperatures in LA by $1.42^{\circ} \mathrm{C}$.

Tree planting is estimated to cost between $\$ 1,022,500,000$ and $\$ 1,363,333,000$ dollars, and cause approximately $.5^{\circ} \mathrm{C}$ of cooling. Trees are clearly effective at cooling, but also provide a myriad of co-benefits. Los Angeles already has a strong tree planting effort in place, through public-private partnerships. While this program has been successful at planting nearly a million trees, LA has room for up to 2.5 million more. Stronger tree planting legislation should be considered, along with a potential ban on tree removal, except in extreme circumstances. Drought-tolerant species should be specified in order to address concerns about drought and water use. Store owners concerned about views of their establishments could be given exceptions to local sign ordinances, allowing them to adapt their signage to be visible despite the tree planting.

Cool pavements are estimated to cost between $\$ 339,057,000$ and $\$ 613,046,016$ and cause $.46^{\circ} \mathrm{C}$ of cooling. Los Angeles staff and internal memos indicate that the City is exploring cool pavements, but has yet to identify a desired material. Cool pavements are clearly effective at causing cooling, therefore additional budget should be allocated in order to cover the cost premium of reflective materials. The introduction of cool pavement materials could begin with small scale demonstration projects, and evolve into a citywide program over time. 
The total cost of implementing cool roofs citywide is estimated to be in the range of $\$ 2,250,000,000$ to $\$ 2,350,000,000$, but will reduce temperatures by $.73^{\circ} \mathrm{C}$. The City of LA already mandates cool roofs for commercial buildings with low-slope roofs, however, residential buildings are not covered under this mandate. The cost premium for cool versions of asphalt shingles (which cover the majority of residential buildings), is much higher than the cost premium for commercial roofing materials, $\$ .64$ to $\$ .20$ respectively. Therefore, in order avoid financially burdening home owners, any legislation to mandate cool roofs on residential buildings should incorporate financial incentives, or be packaged with flexible standards that allow alternative methods of compliance, such as cool pavements or tree planting.

In terms of roofing materials, the findings of this cost-benefit analysis largely confirm the results of previous studies that recommend cool roofs over green roofs and conventional roofs. Sproul et al.'s (2014) life-cycle cost analysis of living roofs, cool roofs, and conventional roofs found that, relative to typical dark colored roofs, living roofs have a negative 50 year net savings of $\$ 6.60$ per square foot. Cool roofs, by contrast, had a positive net savings of $\$ 2.40$ per square foot. They concluded that building owners concerned with local environmental concerns were encouraged to choose living roofs, while owners concerned with global warming should choose cool roofs (Sproul et al., 2014). 
Findings from the cost-effectiveness analysis indicate that solar panels and green roofs should not be prioritized for UHIE mitigation at this time, but may warrant further study. However, solar panels and green roofs may be installed or prioritized for their other benefits, such as energy generation and storm water retention. Lancaster's mandatory solar ordinance serves as a successful model of how to increase solar installations.

Question 2: How politically and socially acceptable are climate adaptation strategies? Findings from stakeholder interviews indicate that political feasibility is high for all strategies except structural shading, which was thought to be costly and difficult to implement, and street trees, because of opposition from business owners who don't wants views of their stores blocked. Overall community support for HIMS is high in LA, but can vary by neighborhood. However, significant barriers to implementation were identified by interviewees. Some neighborhoods may have more pressing social issues to deal with, and may not be enthusiastic supporters of UHIE mitigation measures. Another major barrier to HIMS is a lack of political will and the siloed nature of City government. A champion is needed in City Hall in order to make significant progress. Specific HIMS, such as tree planting and green roofs have several barriers to overcome, including the perception that LA is in a drought, and the need for maintenance.

Findings from the case studies indicate that well designed UHIE mitigation policies are likely to be highly acceptable politically, as none of the case study policies appeared to 
experience any political backlash. This may be due to the emphasis on direct financial incentives to property owners or developers inherent in each policy.

\section{Question 3: How can climate adaptation policies best be implemented?}

Findings from stakeholder interviews indicated that different UHIE measures should be prioritized in different areas, depending on local conditions. For example, tree planting and cool roofs should be prioritized in downtown LA, while solar panels should be prioritized in inland areas. In order to increase the adoption of UHIE measures, possible regulatory incentives for UHIE measures could include compliance with low-impact development standards, a reduced tax burden, decreased regulation, or faster permitting. Mandatory measures may be opposed by business owners, but more flexible ordinances could be better received. The case studies provide examples of successful policies that could be emulated by the City of LA.

Findings from the case studies of Seattle, WA, New York City, NY, Washington D.C. and Lancaster, CA provided examples of successful implementation of strategies to reduce the UHIE. Several lessons can be drawn from these case studies, and inform policy formulation in LA: emphasize the co-benefits and provide financial incentives. Any efforts to pass UHIE reduction policies in LA should make sure to carefully assess the economic implications. Policies that provide financial or performance-based incentives for property owners or developers are likely to be more successful that policies that are inflexible, arbitrary, or financially onerous. 
Climate adaptation policies modeled after examples from other cities must be adapted to local conditions in LA. For example, a living roof incentive based on a storm water fee reduction may be less applicable in LA, which receives approximately 15 inches of rainfall per year, than in Washington D.C., which receives approximately 40 inches of rainfall per year. An LA-specific living roof incentive might be more successful by focusing on UHIE mitigation, with storm water management as a co-benefit. In some cases, a policy should be considered on the merits of co-benefits alone, with UHIE mitigation as a minor driver. The solar policy in case study \#3 was highly successful at encouraging solar panel installation in nearby Lancaster, CA. Although the cost-benefit analysis showed that solar panels are not cost effective for UHIE mitigation, they accomplish the interrelated goal of GHG mitigation.

\subsection{Recommendations}

The following recommendations are derived from the findings of the case studies, personal interviews and cost-effectiveness analysis. This paper focuses on evaluating urban design strategies for citywide UHIE mitigation, and does not evaluate strategies for individual sites or buildings, therefore the findings from this study are relevant to urban planners, policy makers, urban designers, and architects, but not private property owners. Individual recommendations are given for each of these professions. 
For urban planners and policy makers

Findings from the cost effectiveness analysis indicate that planners and policy makers should prioritize cool roofs and pavements over other strategies for UHIE mitigation, with cool pavement and tree planting given secondary priority. While progress has been made towards all three of these strategies, a policy framework which sets goals for UHIE mitigation on citywide scale, as well as the individual property scale, would help to unify various disjointed efforts into one. Citywide goals and objectives specific to climate adaptation (as opposed to GHG mitigation) are necessary to ensure that LA avoids the worst effects of increased heat. Year by year implementation goals for tree planting, cool roofs and cool pavements would help to keep track of the City's progress towards adaptation. The costs of additional tree planting and cool pavement installation would fall on the public sector. Therefore, additional budget should be allocated for these strategies. The costs of cool roofs and solar panels, however, will fall primarily on the private sector.

\section{For urban designers}

There is a clear need for climate adaptation-related urban design interventions in both public (streets, sidewalks and medians) and private space (roofs, parking lots, and private yards). This could be accomplished through flexible design standards which set overall goals for reflectiveness and/or shading. These standards should allow architects and designers to choose from a menu of design strategies, rather than conform to prescriptive materials requirements. Some properties may be better suited to planting 
extra trees, while other properties may be better suited to reflective pavements and cool roofs. However, more effective strategies, such as cool roofs, should be given greater weight in the compliance calculations. An easy-to-use checklist could be developed, similar to Seattle's Green Factor checklist, in which the square footage of various materials is calculated and compared to the site's overall albedo requirements. The costs of compliance with such a system of design standards would fall primarily on the private sector. However, flexible standards would allow individual property owners and designers to minimize their own costs while achieving the minimum standards.

\section{For architects}

Architects in LA should be aware of passive strategies for indoor and outdoor cooling, such as cool roofs, cool pavements, and tree planting. Architects should pursue these strategies not only to help cool the city as a whole, but also to cool the project site, reducing the need for mechanical cooling and therefore saving money over time. In the absence of legislative requirements, architects can act preemptively to increase albedo and shading in their designs, with the expectation that requirements or incentives may be developed in the future.

\subsection{Research Limitations}

For the purposes of this study, certain assumptions were made in order to generalize the physical characteristics of LA, and the cost of implementing UHIE mitigation 
measures. Cost data was based on estimates and industry surveys, rather than actual quoted costs or detailed economic models. Data on the cooling effectiveness of UHIE strategies was based on previous researcher's climate models, which make generalizations about land use and the impact of theoretical changes to the built environment, rather than modeling the complex interactions of actual micro-scale urban design interventions. As a result, this study is intended to be useful to planners and policy makers, rather than urban climatologists. The findings of this study are best utilized as a first step in the evaluation of climate adaptation strategies, or the formulation of a climate adaptation plan, rather than the basis for policy recommendations.

\subsection{Opportunities for Further Study}

Further research evaluating UHIE mitigation measures in LA could focus on more detailed study of the three most cost-effective measures: cool roofs, cool pavements and tree planting. Specifically, studies could examine potential policy options which provide financial incentives to builders and property owners to install these features in new construction and retrofits. Policies which provide financial incentives were found to be highly successful in other cities, and could be equally successful in LA.

The cost effectiveness analysis was conducted primarily to rank the HIMSs, rather than for budgeting or cost estimation. Further research may be necessary to accurately 
project how costs change with unit cost increase, and over time. A cost effectiveness analysis was not performed for structural shading, as the installation of shade structures would vary so widely in terms of cost. However, this strategy does appear to be effective at UHIE mitigation and therefore warrants further study. 


\section{BIBLIOGRAPHY}

Akbari, H., Davis, S., Dorsano, S., \& Huang, J. (1992). Cooling Our Communities: A Guidebook on Tree Planting and Light-Colored Surfacing. A Report to the United States Environmental Protection Agency. Report number 22P.2001. Retrieved from http://escholarship.org/uc/item/98z8p10x.

Alcoba, N. (2011). City may ease green roof rules on new buildings. The National Post. Retrieved from http://news.nationalpost.com/2011/11/08/city-may-easegreen-roof-rules-on-new-buildings/.

Ban-Weiss, G.A, Woods, J., \& Levinson, R. (2014). Using remote sensing to quantify albedo of roofs in seven California cities, Part 1: Methods. Solar Energy. In Press.

Barringer, F. (April 8, 2013). With Help From Nature, a Town Aims to Be a Solar Capital. New York Times. Retrieved from http://www.nytimes.com/2013/04/09/us/lancaster-calif-focuses-on-becomingsolar-capital-of-universe.html?_r=0.

Boixo, S., Diaz-Vicente, M., Colmenar, A., \& Castro, M.A. (2012) Potential energy savings from cool roofs in Spain and Andalusia. Energy, 38, 425-438.

Borden, K.A, \& Cutter, S.L. (2008). Spatial patterns of natural hazards mortality in the United States. International Journal of Health Geographics, 7 (64). Retrieved from http://www.ij-healthgeographics.com/content/7/1/64.

Bornstein, R.D. (1968). Observations of the urban heat island effect in New York City. Journal of Applied Meteorology, 7, p 575-582. Retrieved from http://www.met.sjsu.edu/faculty/bornstein/old/NYCNYU/UHI-NYU-1968.pdf.

Bowler, D.E., Buyung-Ali, L., Knight, M.T., \& Pullin, S.A. (2010). Urban greening to cool towns and cities: A systematic review of the empirical evidence. Landscape and Urban Planning, 97 (3), 147-155.

California Department of Transportation (CalTrans). (2011). 2011 contract cost data. Retrieved from http://www.dot.ca.gov/hq/esc/oe/awards/. 
California Emergency Management Agency (CalEMA). (n.d.). What is hazard mitigation? Retrieved from http://hazardmitigation.calema.ca.gov/docs/About_Hazard_Mitigation.pdf.

California Natural Resources Agency. (2009). California Climate Adaptation Strategy. Retrieved from http://resources.ca.gov/docs/climate/Statewide_Adaptation_Strategy.pdf.

California Solar Statistics. (February, 2015). Geographical solar statistics for capacity and installations. Retrieved from http://californiasolarstatistics.ca.gov/reports/locale_stats/.

Cayan, D., Tyree, M., Dettinger, M., Hidalgo, H., Das, T., Maurer, E., Bromirski, P., Graham, N., \& Flick, R. (2009). Climate change scenarios and sea level rise estimates for the California 2008 climate change scenarios assessment. California Climate Change Center. Retrieved from http://www.energy.ca.gov/2009publications/CEC-500-2009-014/CEC-5002009-014-F.PDF.

Centers for Disease Control and Prevention. (2012). Deaths and mortality. Retrieved from http://www.cdc.gov/nchs/fastats/deaths.htm.

Climate action plans. (n.d.). From Institute for Local Government. Retrieved on November 11, 2014 from http://www.ca-ilg.org/climate-action-plans.

Cool roof rating council. (n.d.). Cool roofing information for home and building owners. Retrieved from http://coolroofs.org/resources/home-building-owners.

District of Columbia, Municipal regulations title 21, chapter 21-5, section 21-566. Stormwater fees. (2014). Retrieved from http://www.dcregs.dc.gov/Gateway/FinalAdoptionHome.aspx?RuleVersionID= 3678451.

Dodson, M. (2001). The growing western roofing market. Western roofing insulation and siding. Retrieved from www.westernroofing.net.

Downtown Seattle Association. (2015). Development and construction projects. Retrieved from http://www.downtownseattle.com/resources/development-andconstruction-projects/ 
Erell, E. Pearlmutter, D. \& Williamson, T. (2011). Urban Microclimate: Designing the Spaces Between Buildings. Earthscan, Washington D.C.

Gartland, L. (2008). Heat islands: Understanding and mitigating heat in urban areas. Earthscan press, London.

Gillespie, T., Pincetly, S., Brossard, S., Smith, J., Saatchi, S., Pataki, D. \& Saphores, J. (2012). A time series of urban forestry in Los Angeles. Urban Ecocyst, 15, 233-246.

Global Warming Solutions act of 2006. (2006). Division 25.5, section 38500 , California Health and Safety Code. Retrieved from http://www.leginfo.ca.gov/pub/05-06/bill/asm/ab_00010050/ab_32_bill_20060927_chaptered.pdf.

Goodrich, A., James, T. \& Woodhouse, M. (2012). Residential, commercial, and utility scale photovoltaic system prices in the United States: current drivers and cost-reduction opportunities. National Renewable Energy Laboratory: Technical report. Retrieved from http://www.nrel.gov/docs/fy12osti/53347.pdf.

Go Solar California. (2014). Cost by quarter. Retrieved from http://californiasolarstatistics.ca.gov/reports/quarterly_cost_per_watt/.

Go Solar California. (2014). Geographical statistics, data retrieval. Retrieved from http://www.californiasolarstatistics.ca.gov/reports/locale_stats/.

Green LA: An Action Plan to Lead the Nation in Fighting Global Warming. (2007). Retrieved from http://environmentla.org/pdf/GreenLA_CAP_2007.pdf.

Green roofs for healthy cities. (2014). 2013 Annual Green Roof Industry Survey. Retrieved from http://www.greenroofs.org/resources/GreenRooflndustrySurveyReport2013.pd f.

Gregerson, J. (2010). Cool pavement generates hot debate. Buildings, 104 (9), 5457. Retrieved from http://www.buildings.com/articledetails/articleid/10485/title/cool-pavement-generates-hot-debate.aspx. Guinn, J.M. (1915). A History of California and an Extended History of Los Angeles and Environs, Vol. 1. Los Angeles: Historic Record Company. 
Guyenet, J. (2009). Cool roofs. Environmental design and construction, 12 (10), 3840.

Haider, T. (1997). Urban climates and heat island: albedo, evapotranspiration, and anthropogenic heat. Energy and Buildings, 25 (2), 99-103.

Hall, A., Sun, F., Walton, D., Capps, S., Qu, X., Huang, H., Berg, N. Jousse, A., Schawrtz, M., Nakamura, M. \& Cerezo-Mota, R. Mid-Century Warming in the Los Angeles Region - Part I of the "Climate Change in the Los Angeles Region" project. (2012). Institute of the Environment and Sustainability, UCLA. Retrieved from http://c-change.la/pdf/LARC-web.pdf.

He, J.F., Liu, J.Y., Zhuang, D.F., Zhang, W., \& Liu, M.L. (2007). Assessing the effect of land use land cover change on the change of urban heat island intensity. Theoretical and applied climatology, 90, 217-226. Retrieved from http://download.springer.com/static/pdf/19/art\%253A10.1007\%252Fs00704006-02731.pdf?auth66=1384019940_b16297ca1b929b4af1ecb49fecdfa567\&ext=.pdf.

Homewyse.com. (n.d.). Database search, average cost to install shingle roof. Retrieved from http://www.homewyse.com/services/cost_to_install_shingle_roof.html.

Horowitz, C. (October, 2011). Bright roofs, big city: Keeping L.A. cool through an aggressive cool-roof program. Pritzker briefs, UCLA School of Law. Retrieved from http://www.coolrooftoolkit.org/wp-content/uploads/2012/05/UCLABright_Roofs_Big_City.pdf.

Hui, L. (2012). Evaluation of cool pavement strategies for heat island mitigation. n. p. ProQuest, UMI Dissertations Publishing.

International Panel on Climate Change. (2007). Fourth assessment report: Climate change 2007. Retrieved from http://www.ipcc.ch/publications_and_data/ar4/wg2/en/annexessglossary-ad.html.

Ireland, P. (2012). Climate change adaptation: Business-as-usual aid and development or an emerging discourse for change? International Journal of Development Issues, 11, 92-110. 
John, J. (2013). AB 327 Signed into law in California, with solar NEM warning from Jerry Brown. Greentech solar. Retrieved from http://www.greentechmedia.com/articles/read/AB-327-Signed-Into-Law-inCalifornia-With-Solar-NEM-Warning-from-Jerry-Bro.

Jones, C. (2012). Seattle's Green factor. BiophilicCities. Retrieved from http://biophiliccities.org/seattles-green-factor/.

Kosareo, L., \& Ries, R. (2006). Comparative environmental life cycle assessment of green roofs. Building and Environment, 42, 2606-2613. Retrieved from http://ac.els-cdn.com/S0360132306001648/1-s2.0-S0360132306001648main.pdf?_tid=3c7d2a40-6a04-11e4-b87800000aabOf6b\&acdnat=1415752895_b7184b68ab3d11a1e9e55a616f05eb11

Kovats, R.S. \& Hajat, S. (2008). Heat Stress and Public Health: A Critical Review. Annual Review of Public Health, 29, 41-55. Retrieved from http://www.annualreviews.org/doi/pdf/10.1146/annurev.publhealth.29.020907. 090843.

Lancaster, City of. (2013). Residential zones update. Retrieved from http://www.cityoflancasterca.org/index.aspx?page $=1279$.

Leonard O. Myrup. (1969). A numerical model of the urban heat island. Journal of Applied Meteorology, 8(6), 908-918. Retrieved from: http://journals.ametsoc.org/doi/pdf/10.1175/15200450(1969)008<0908:ANMO TU>2.0.CO;2.

Levinson, R. \& Akbari, H. (2001). Effects of composition and exposure on the solar reflectance of Portland cement concrete. Lawrence Berkeley Nation Laboratory. Retrieved from https://escholarship.org/uc/item/5h77n60m\#page1.

Levinson, R. Akbari, H. Konopacki, S. \& Bretz, S. (2002). Inclusion of cool roofs in nonresidential title 24 prescriptive requirements. Lawrence Berkeley National Laboratory. Retrieved from http://www.osti.gov/scitech/servlets/purl/813562. 
Levinson, R. \& Akbari, H. (2010). Potential benefits of cool roofs on commercial buildings: conserving energy, saving money, and reducing emission of greenhouse gases and air pollutants. Energy efficiency, 3, 53-109.

Liu, J., Zeng, S., Ng, E., Chen, L., Wang, Y., \& Yuan, C. (2012). A study on the cooling effects of greening in a high-density city: An experience from Hong Kong. Building and Environment, 47, 256-271. Retrieved from http://www.sciencedirect.com/science/article/pii/S0360132311002228.

Los Angeles, City of. (1996). Landscape ordinance. Retrieved from cityplanning.lacity.org/.../landsc\%20guidelines\%204-05.pdf.

Los Angeles, City of, Department of City Planning. (2011). Citywide Design Guidelines. Retrieved from http://cityplanning.lacity.org/Policylnitiatives/UrbanDesign/CDGPolicy_Vote_G uidelines.pdf.

Los Angeles, City of. (2011). Los Angeles Green Building Code Ordinance (LA $\mathrm{GBC})$. Retrieved from http://ladbs.org/LADBSWeb/LADBS_Forms/Publications/LAGreenBuildingCod eOrdinance.pdf.

Los Angeles, City of. (2013). Cool pavements, Save our Streets LA. Interdepartmental correspondence. Retrieved from cao.lacity.org/SOSLA/9_CoolPavement.pdf.

Los Angeles, City of, Environmental Services Group. (2014). Personal communication regarding the cost of tree planting.

Manville, M., \& Shoupe, D. (2004). People, parking and cities. Access, no. 25. Retrieved from http://shoup.bol.ucla.edu/People,Parking,Cities.pdf.

Mazouz, S. \& Zeroula, M.S. (1998). Shading as a modulator for the design of urban layouts based on vernacular experiences. Energy and Buildings, 29 (2), 1115.

Mazouz, S. \& Zeroula, M.S. (1999). The derivation and re-use of vernacular urban space concepts. Architectural Science Review, 21(2), 3-13. 
McPherson, G.E., Simpson, J.R., Xiao, Q., \& Wu, C. (2008). Los Angeles 1-milion tree canopy cover assessment. United States Department of Agriculture, Forest Service, Pacific Southwest Research Station. General Technical Report PSW-GTR-207.

Miller, C. (March 9, 2011). Shady dealings: or the problem with planting trees in Los Angeles. KCET. Retrieved from http://www.kcet.org/updaily/socal_focus/commentary/31213-los-angelesmillion-trees-villaraigosa.html.

Miller, R. (n.d.). The average life of roofing. Retrieved from http://homeguides.sfgate.com/average-life-roofing-94238.html.

National Oceanic and Atmospheric Administration. (2013). Online Weather Data query: Los Angeles/Oxnard weather database. Retrieved from http://www.nws.noaa.gov/climate/xmacis.php?wfo=lox.

National Oceanic and Atmospheric Administration. (2014). NOAA Online Weather Data query. National Weather Service Weather Forecast Office, Washington D.C. and Chicago. Retrieved from http://www.crh.noaa.gov/lot/?n=111577_Midway.

New York, City of. (2011). Local laws of the City of New York, No. 21. Retrieved from http://www.nyc.gov/html/coolroofs/downloads/pdf/ll21 of2011.pdf.

New York, City of. (2013). Cool roofs annual review 2012. Retrieved from http://www.nyc.gov/html/coolroofs/downloads/pdf/CoolRoofsPresentation2013 -FINAL.pdf.

$\mathrm{Ng}$, Edward, Liu, Junjie; Zeng, Shanying; Chen, Liang; Wang, \& Yingna et al. (2012). A study on the cooling effects of greening in a high-density city: An experience from Hong Kong. Building and Environment, 47, 256-27. Retrieved from http://www.sciencedirect.com/science/article/pii/S0360132311002228.

Nichols Engineers. (2012). Cool Pavements study. Retrieved from www.chulavistaca.gov/clean/PDF/CVCoolPavementsStudy_DRAFT9-712.pdf. 
Oberdorfer, E., et al. (2007). Green Roofs as Urban Ecosystems: Ecological Structures, Functions, and Services. Bioscience, 57 (10), 823-833.

Oke, T.R. (1973). City size and the urban heat island. Atmospheric Environment, 7 (8), 769-779.

Parker, D.S., Barkaszi, S.F., Chandra, S. \& Beal, D.J. (1995). Measured cooling energy savings from reflective roofing systems in Florida: field and laboratory research results. Florida Energy Center and Lawrence Berkeley National Laboratory.

Pincetl, S., Gillespie, T., Pataki, D.E., Saatchi, S., \& Sapores, J.D. (2012). Urban tree planting programs, function or fashion? Los Angeles and urban tree planting campaigns. Geojournal, 78 (3), 475-493.

Public Research Energy Program. (2009). Temperature: Degrees of change map, Los Angeles [data file]. Retrieved from http://caladapt.org/temperature/century/.

Pueblo de Los Angeles. (n.d.). Wikipedia. Retrieved from http://en.wikipedia.org/wiki/Pueblo_de_Los_\%C3\%81ngeles\#cite_note-6.

Rangaraju, P.R., Amirkhanian, S. \& Guven, Z. (2008). Life cycle cost analysis for pavement type selection. South Carolina Department of Transportation. Retrieved from http://www.clemson.edu/t3s/scdot/pdf/projects/SPR656Final.pdf.

Roof shingle. (n.d.). Wikipedia. Retrieved from http://en.wikipedia.org/wiki/Roof_shingle.

Rose, Akbari \& Taha. (2003). characterizing the fabric of the urban environment: a case study of greater Houston, Texas. Paper LBNL-51448. Lawrence Berkeley National Laboratory, Berkeley, CA.

Rosenberg, J. (July 9, 2012). Laws that shaped LA: How Thomas Jefferson made LA. KCET. Retrieved from http://www.kcet.org/socal/departures/columns/laws-that-shaped-la/howthomas-jefferson-made-the-streets-of-la.html. 
Rosenberg, J. (January 9, 2012). Laws that shaped LA: Why Los Angeles isn't a beach town. KCET. Retrieved from http://www.kcet.org/socal/departures/columns/laws-that-shaped-la/the-lawsthat-shaped-la-laws-of-the-indies.html.

Rosenfeld, A.H., Akbari, H., Bretz, S., Fishman, B.L., Kurn, D.M., Sailor, D., Taha, H. (1995). Mitigation of urban heat islands: materials, utility programs, updates. Energy and Buildings, 22, 255-265.

Rosenfeld, A.H., Akbari, H. Romm, J.J., \& Pomerantz, M. (1998). Cool communities: strategies for heat island mitigation and smog reduction. Energy \& buildings, 28, 51-62.

Sailor, D.J., \& Dietsch, N. (2005). The urban heat island mitigation screening tool. Retrieved from http://www.heatislandmitigationtool.com/Documents/detailed_help.pdf.

Sargent, R. Burr, J., Dutziak, T. \& Schneider, J. (2014). Shining cities: At the forefront of America's solar revolution. Environmental America Research and Policy Center. Retrieved from http://www.environmentcaliforniacenter.org/sites/environment/files/reports/CA _shining_cities_scrn.pdf.

Seattle, City of. (2007). Seattle/ green factor. Retrieved from http://www.seattle.gov/dpd/cs/groups/pan/@pan/documents/web_information al/dpds021348.pdf.

Simpson, J.R. (1998). Urban forest impacts on regional cooling and heating energy use: Sacramento county case study. Journal of arboriculture, 24 (4).

South Coast Air Quality Management District (SQAQMD). (2012). Air Quality Management Plan. Retrieved from http://www.aqmd.gov/docs/defaultsource/clean-air-plans/air-quality-management-plans/2012-air-qualitymanagement-plan/final-2012-aqmp-\%28february-2013\%29/main-documentfinal-2012.pdf.

Sproul, J., Wan, M.P., Mandel, B.J. \& Rosenfeld, A.H. (2014). Economic comparison of white, green and black flat roofs in the United States. Energy and Buildings, $71,20-27$. 
Streets for the Future Coalition. (2014). Policy recommendations. Retrieved from http://www.aialosangeles.org/pdf/Press\%20Releases/Streets\%20for\%20the\% 20Future.pdf.

Swan, D. (Jan 06, 2014). Why roof-top solar panels really don't make sense. Energybiz.com. Retrieved from http://www.energybiz.com/article/14/01/whyroof-top-solar-panels-really-dont-make-sense

Taha, H. (2008). Meso-urban meteorological and photochemical modeling of heat island mitigation. Atmospheric environment, 42 (38), 8795-809.

Taha, H. (2011). Air-Quality Impacts of Heat Island Control and Atmospheric Effects of Urban Solar Photovoltaic Arrays. California Energy Commission.

Publication number CEC-500-2013-061. Retrieved from http://www.energy.ca.gov/2013publications/CEC-500-2013 061/CEC-5002013-061.pdf.

Taha, H. (2013). Ranking and prioritizing the deployment of community-scale energy measures based on their indirect effects in California's climate zones. Altostratus, Inc. Retrieved from http://www.energy.ca.gov/2013publications/CEC-500-2013-122/CEC-5002013-122.pdf

Taha, H. \& Chang, S.C. (2009). Meteorological and Air Quality Impacts of Heat Island Mitigation Measures in Three U.S. Cities. Lawrence Berkeley National Laboratory, Berkeley, CA. Retrieved from http://www.epa.gov/hiri/resources/pdf/3_cities.pdf.

Than, K. (2013). As solar power grows, dispute flares over U.S. utility bills. National Geographic. Retrieved from http://news.nationalgeographic.com/news/energy/2013/12/131226-utilitiesdispute-net-metering-for-solar/.

The California Climate Change Center. (2006). Our Changing Climate, Assessing the Risks to California. Retrieved from http://meteora.ucsd.edu/cap/pdffiles/CA_climate_Scenarios.pdf.

The Laws of the Indies. (n.d.). The Encyclopedia Britannica online. Retrieved from http://www.britannica.com/EBchecked/topic/286140/Laws-of-the-Indies. 
Trabish, H.K. (March 27, 2013). Lancaster, CA Becomes First US City to Require Solar. Greentech Solar. Retrieved from http://www.greentechmedia.com/articles/read/Lancaster-CA-Becomes-FirstUS-City-to-Require-Solar.

Trinity Exteriors, Inc. (2009). Case study: are reflective shingles worth it. Retrieved from http://www.trinityexteriorsinc.com/1108/case-study-are-energy-star-coolshingles-worth-it.

Tuhus-Dubrow, R. (May 28, 2014). On a cool-roof: City planners, activists, and researchers debate climate change. Nextcity.org. Retrieved from http://nextcity.org/daily/entry/cool-roofs-climate-change-debate.

United States Conference of Mayors. (2012). U.S. Metro economies. Retrieved from http://usmayors.org/metroeconomies/0712/FullReport.pdf.

United States Environmental Protection Agency. (2008). Reducing urban heat islands: a compendium of strategies. Retrieved from http://www.epa.gov/heatisland/resources/compendium.htm.

United States Environmental Protection Agency. (2013). Our built and natural environment: A technical review of the interactions among land use, transportation, and environmental quality. Retrieved from http://www.epa.gov/dced/pdf/b-and-n/b-and-n-EPA-231K13001.pdf.

United States Government, Code of Regulations. (2014). Definition of "hazard mitigation". Section 44, subpart M, section 206.401.

Urban design. (n.d.). In Wikipedia. Retrieved November 11, 2014, from http://en.wikipedia.org/wiki/Urban_design.

Vanos, J.K., Kalkstein, L.S., Sailor, D., Shickman, K., \& Sheridan, S. (2014). Assessing the health impacts of urban heat island reduction strategies in the cities of Baltimore, Los Angeles, and New York. Global Cool Cities Alliance. Retrieved from http://www.coolrooftoolkit.org/wpcontent/uploads/2014/07/Three-City-Heat-Health-Report-FINAL-adj.pdf. 
Western Regional Climate Center. (2014). Los Angeles Civic Centre, California, Monthly Total Cooling Degree Days. Retrieved from http://www.wrcc.dri.edu/cgi-bin/cliMONtcdd.pl?ca5115.

Wheeler, L. (2008). Overflows cost sewer systems $\$ 35$ million in fines. Gannet News Service. Retrieved from http://usatoday30.usatoday.com/news/nation/200805-07-sewers-facts_N.htm.

Yang, J., Wang, Z., \& Kaloush, K.E. (2014). Unintended consequences: a research synthesis examining the use of reflective materials to mitigate the urban heat island effect. White paper. Retrieved from https://ncesmart.asu.edu/docs/smart/unintended-consequences-1013.pdf 